\title{
The quantum and tempo of life-cycle events
}

John Bongaarts

Population Council

Griffith Feeney

Follow this and additional works at: https://knowledgecommons.popcouncil.org/departments_sbsr-pgy

Part of the Demography, Population, and Ecology Commons

How does access to this work benefit you? Let us know!

\section{Recommended Citation}

Bongaarts, John and Griffith Feeney. 2005. "The quantum and tempo of life-cycle events," Policy Research Division Working Paper no. 207. New York: Population Council. Version of record: https://doi.org/ 10.1553/populationyearbook2006s115 


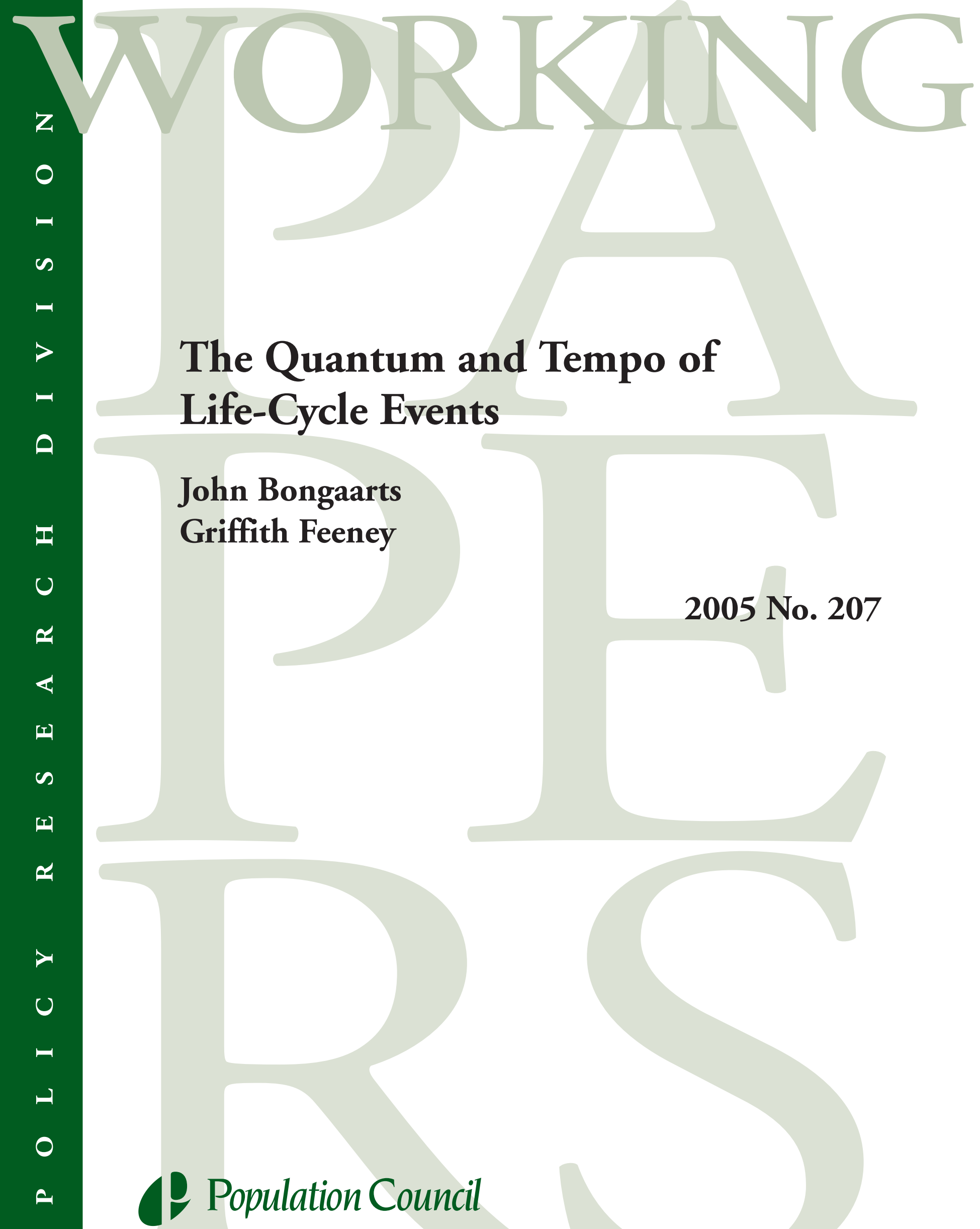




\section{(P) Population Council}

One Dag Hammarskjold Plaza

New York, New York 10017 USA

www.popcouncil.org

pubinfo@popcouncil.org

This material may not be reproduced without written permission from the authors. For a list of Policy Research Division Working Papers, including those that are currently available for downloading in PDF format, see www.popcouncil.org/publications/wp/prd/rdwplist.html.

ISSN: $1554-8538$

(C) 2005 The Population Council, Inc. 


\title{
The Quantum and Tempo of Life-Cycle Events
}

\author{
John Bongaarts \\ Griffith Feeney
}

John Bongaarts is Vice President, Policy Research Division, Population Council, New York. Griffith Feeney is a demographer and consultant based in Scarsdale, New York.

Paper prepared for the conference on Postponement of Childbearing in Europe: How Much More and Why?, organized by the Vienna Institute of Demography, Vienna, December 1-3, 2005. An earlier version was presented at the Mortality Tempo Workshop sponsored by the Max Planck Institute for Demographic Research and the Population Council, New York, November 18-19, 2004. 


\begin{abstract}
:
This study develops and applies a general framework for the analysis of the period quantum and tempo of life-cycle events, extending methods developed previously by the authors. The existence of tempo distortions is demonstrated in selected period quantum measures such as the total fertility rate and in period tempo measures such as life expectancy. A tempo distortion is defined as an undesirable inflation or deflation of a period quantum or tempo indicator of a life-cycle event, such as birth, marriage, or death, that results from a rise or fall in the mean age at which the event occurs. Period measures derived from life tables are also found to be subject to distortion. Methods to remove these tempo distortions are then developed and applied.
\end{abstract}


Questions about human life-cycle events are central to demographic analysis and to social and health policies. How many children do we have? How long do we live? What proportion of men and women ever marry? When do we retire? How much time in old age is spent in good health?

To answer such questions standard demographic methods have been developed to measure key dimensions of the distribution of events over the life cycle. Attention usually focuses on the two primary components of these distributions, the level or quantum component and the timing or tempo component. Quantum is measured as the average number of events over the course of the life cycle, in the absence of competing events, and tempo as the mean age at the event. The total fertility rate is a quantum measure of fertility, for example, and life expectancy at birth is a tempo measure of mortality.

The quantum and tempo of events can be measured either for cohorts, to summarize the actual experience of a group of persons born in the same year, or for periods, to describe the experience of a hypothetical cohort subject to the conditions observed in a given time period. Cohort measures of quantum and tempo are easily and unambiguously obtained by following a cohort over time until it reaches an age at which the risk of the event equals zero.

Period measures of quantum and tempo, though conceptually more difficult, are far more widely used for two main reasons. First, because cohort indicators measure ongoing changes in demographic processes after a lag, they cannot adequately describe year-to-year changes. Second, period measures require less historical data than cohort measures and may therefore be calculated for many more countries and more times.

This study develops and applies a general framework for the analysis of the period quantum and tempo of life-cycle events, extending methods developed in Bongaarts and Feeney $(1998 \mathrm{a}, 2002,2003)$. We begin with a brief presentation of the two main types of age-specific rates from which period quantum and tempo measures are calculated. The remainder of the study is divided into two parts corresponding to the two types of rates. Both of these parts demonstrate the existence of tempo distortions in selected period quantum and tempo measures. A tempo distortion is defined as an undesirable inflation or deflation of a period quantum or tempo indicator of a life-cycle 
event, such as birth, marriage, or death, that results from a rise or fall in the mean age at which the event occurs. We then develop and apply methods to remove these tempo distortions.

\section{Background: Age-specific event rates}

Two types of age-specific rates are used in demographic analysis (Henry,1972; Sobotka, 2003, 2004a; Kohler and Ortega, 2002a).

Rates of the 1st kind, illustrated by standard age-specific death rates, are quotients in which the numerator counts events occurring to persons at age $a$ and time $t$ and the denominator counts persons at age $a$ and time $t$ exposed to the risk of the event in question. Rates of the 1st kind are also called risks, hazards, intensities, conditional rates, and occurrence-exposure rates. For the life-cycle events considered in this paper, first birth, first marriage, and death, persons exposed to risk are those who have not already experienced the event.

Rates of the 2nd kind, illustrated by standard age-specific birth and marriage rates, are quotients in which the numerator counts events occurring to persons at age $a$ and time $t$ and the denominator counts all persons at age $a$ and time $t$, including those who have already experienced the event. Rates of the 2nd kind are also called densities, unconditional rates, reduced rates, incidence rates, and frequencies.

The relation between rates of the 1 st and 2 nd kinds is straightforward for first births, first marriages, and death. The denominators of rates of the 1st kind exclude persons who have already experienced the event, whereas the denominators of rates of the 2nd kind include these persons. This relationship may be expressed using life table notation as $\mu(a, t)=d(a, t) / p(a, t)$, where $\mu(a, t)$ denotes a rate of the 1 st kind, $d(a, t)$ a corresponding rate of the 2 nd kind, and $p(a, t)$ denotes the proportion of persons born at time $t-a$ who have not experienced the event by age $a$.

The relation between the two kinds of rates for events that can occur more than once in a lifetime (recurrent events) is more complicated. The established way of dealing with recurrent events is to number events in order of occurrence to each individual. For example, births are divided into first births, second births, third 
births, and so on. In this way any recurrent event may be resolved into a series of non-recurrent events, which can be analyzed separately.

Table 1 displays and compares the two kinds of rates for first birth, first marriage, and death. The first row shows clearly the distinction between rates of the 1st and 2 nd kind. The numerators of the two rates are the same (first births), but the denominators of rates of the 1st kind exclude women who have already had a first birth, whereas the denominators of rates of the 2nd kind include these women. Summing these rates of the 2nd kind for all birth orders gives the standard age-specific birth rates from which the total fertility rate is calculated.

The second row of Table 1 shows the two kinds of rates for first marriages. As in the case of first births, the numerators of the two rates are the same. The denominators of rates of the 1st kind exclude women who have already married, whereas the denominators of rates of the 2nd kind include these women.

The last row of the table shows the two kinds of rates for death. The rates of the 1st kind are standard age-specific death rates or, given the continuous formulation, the force of mortality. As in the case of the rates for first birth and first marriage, the numerators of the two kinds of death rates are the same, but the denominators of the rates of the 1st kind exclude persons who have already experienced the event-i.e., persons who have died - whereas the denominators of rates of the 2 nd kind include these persons. Thus the denominators of the death rates of the 2 nd kind include persons in the cohort who have already died as well as those who are living.

Death rates of the 2nd kind are obviously unconventional, for although the quotient shown is a standard demographic statistic - the value of $d(x)$ in the cohort life table for persons born at time $t-a$ - this statistic has not generally been regarded as comparable to the other frequencies shown in the table. Indeed, it is only regarded in this way in a very few studies, e.g., by Sardon $(1993,1994)$ and Bongaarts and Feeney $(2002$, 2003).

Death rates of the 2nd kind are strictly analogous to first birth rates and first marriage rates of the 2nd kind. For all three events, the denominator includes persons who have not yet experienced the event as well as persons who have already experienced the event. The characterization of the denominator for death rates of the 2nd kind appears 
exceptional only because "persons" usually connotes "living persons," though of course it may refer to deceased persons as well.

An important general property of rates of the 2 nd kind is that the sum (integral) of these rates over all ages for a birth cohort gives the average number of events per individual in the cohort. Thus summing age-specific first birth rates gives the average number of first children per woman, and summing age-specific first marriage rates gives the average number of first marriages. The sum of the death rates of the 2 nd kind over all ages for a birth cohort will equal one because the average number of deaths per individual in the cohort necessarily equals one.

In general, the estimation of quantum and tempo measures is straightforward for cohorts, but problematic for periods.

\section{PART I: PERIOD QUANTUM AND TEMPO MEASURES OF THE 2ND KIND}

\section{Standard equations for quantum and tempo measures}

Table 2 presents general equations for calculating period quantum and tempo from rates of the 2 nd kind and specific results for first birth, first marriage, and death. The total event rate $T E R(t)$ and the mean age at event $M A E(t)$ are defined by the formulas in the first row of the table, with $d(a, t)$ denoting the age-specific rate of the 2 nd kind for any of the events shown. The total event rate equals the average number of events over the life cycle for a hypothetical cohort subjected to the rates at time $t$ (in the absence of competing events). For events that occur only once, the total event rate equals the proportion of persons in the hypothetical cohort who ever experience the event.

The quantum and tempo measures of first birth and first marriage in Table 2 are standard tools in demographic analysis and estimates are available for many countries. The total mortality rate and the mean age at death (birth cohort normalized), though defined in precise analogy with the fertility and mortality measures, were introduced for the first time by Sardon $(1993,1994)$ and further analyzed in Bongaarts and Feeney (2002, 2003; note that $M A D(t)$ is not the crude mean age of deaths occurring at time $t$ because the effects of variations in cohort size are removed). The table therefore

illustrates that measures that are standard for some demographic processes may be unknown in the study of other processes. 
Figures 1 to 3 present empirical results for the quantum and tempo measures summarized in Table 2 for selected populations. Figure 1 shows total fertility rates for birth order one, $\operatorname{TFR}_{1}(t)$, and the mean age at first birth, $M A B_{1}(t)$, for the United States from 1950 to 2000 . Values of $T F R_{l}(t)$ exceeded one for most of the $1950 \mathrm{~s}$, an obvious anomaly since no woman can have more than one first birth. This period of elevated fertility coincided with the decline in the age at first birth during the baby boom years of the 1950 s.

Figure 2 shows total first marriage rates, $T N R_{1}(t)$, and the mean age at first marriage, $M A M_{l}(t)$, for France from 1960 through 2001. The above-one rates for France in the early 1960s are anomalous because a woman can experience at most one first marriage. The apparent explanation, by analogy with that for first births, is the declining mean age at first marriage. First marriage rates for France decline over the period shown, with values around 0.5 toward the end of the period. Similar trends are observed in many other European countries, but proportions ever married for cohorts born in the late 1960s are much higher than 0.5 (Council of Europe, 2002). This suggests that the low first marriage rates are distorted.

Figure 3 shows total mortality rates, $T M R(t)$, and the mean age at death, $M A D(t)$, for England and Wales from 1975 to 1998. (For reasons given below all mortality measures in this study include adult mortality above age 30 only.) The total mortality rate is well below one (0.85-0.90). Since every person dies once, any total mortality rate other than one is anomalous. Mortality tempo (MAD) rose sharply throughout the period, and the analogy for first birth and first marriage therefore suggests again that this is the reason for the TMR values different from one.

\section{Tempo effects}

We will now demonstrate that the various anomalies evident in Figures 1, 2, and 3 are largely attributable to tempo effects. A tempo effect is defined as an inflation or deflation of the number of events that are observed in a period when the period mean age at the event changes. The tempo effect causes undesirable distortions of quantum and tempo measures derived from age-specific event rates that contain tempo effects. This section presents the theoretical basis for this effect and offers additional empirical evidence supporting the theory. 


\subsection{Theoretical basis for tempo effects}

Norman B. Ryder made a series of fundamental contributions to the study of quantum and tempo measures $(1956,1959,1964,1980,1983)$. His paradigmatic contribution was a simple model that showed that the period total fertility rate (TFR) does not, in general, equal the cohort completed fertility rate $(C F R)$ even if fertility has been constant for a long period of time. His "translation" formula

$$
T F R=C F R\left(1-r_{c}\right)
$$

shows that the TFR in a constant fertility population tends to be lower than the CFR when the cohort mean age at childbearing is rising (i.e. the rate of change in this mean, $r_{c}$, is positive and hence $\left.\left(1-r_{c}\right)<1\right)$ and higher than the $C F R$ when the mean age at childbearing is falling $\left(r_{c}\right.$ is negative, $\left.\left(1-r_{c}\right)>1\right)$. This equation assumes linearity in time trends of the age-specific fertility rates. Ryder refers to $\left(1-r_{c}\right)$ as an "index of fertility distortion" and he considered the TFR to be a distorted measure when the fertility tempo changes.

Ryder's analyses of period fertility trends in the United States (1980, 1983) showed how changes in the timing of childbearing among cohorts of women influenced annual age-specific birth rates and total fertility rates. When women shift upward the ages at which they bear children, annual numbers of births tend to be deflated because the same number of births will be spread out over a longer time period (e.g., during the 1970s and 1980s). Similarly, when age at childbearing shifts to younger ages, total fertility rates tend to be inflated because the same number of births are compressed into a shorter time period (e.g., during the late 1940s and 1950s).

Zeng and Land (2002) extend Ryder's analysis by deriving the following translation formula,

$$
T F R=C F R\left(1-r_{p}\right),
$$

where $r_{p}$ denotes the rate of change in the period mean age at childbearing and TFR, $C F R, r_{p}$, and the shape of the schedule of age-specific fertility rates are assumed constant. They consider this alternative version of the translation equation preferable to (1) because their constant shape assumption is more realistic than Ryder's linearity assumption. ${ }^{1}$ The conditions under which (2) holds (i.e., constant quantum, fixed rate of increase in the 
period mean, and an invariant shape) will collectively be referred to as the "translation assumptions."

These translation equations were developed for the analysis of fertility trends, but analogous equations apply to other life-cycle processes provided that the same translation assumptions apply. For mortality, for example, we have

$$
T M R=C M R\left(1-r_{p}\right),
$$

where $T M R$ is the total mortality rate, CMR denotes the cohort completed mortality rate, and $r_{p}$ is the rate of change in the period mean age at death, MAD (see Table 2). Because everyone dies once, the $C M R$ equals 1 and (3) simplifies to

$$
T M R=1-r_{p}
$$

This result shows the operation of the tempo distortion in its most basic form: the $T M R$ simply equals the distortion index. The undistorted value of $T M R=1$ is obtained only if the mean age at death is constant (i.e. $r_{p}=0$ ). Any change in the mean age at death, whether up or down, results in a tempo distortion in the total mortality rate and in the mortality rates of the 2 nd kind from which it is calculated. This distortion is evident in Figure 3, which shows that estimates of TMR for England and Wales is about 0.86. This is more or less consistent with the rate of change in the mean age at death shown in Figure 3, about 0.14 years per year.

The period-cohort translation formulas of Ryder (1) and Zeng and Land (2) may be applied when fertility is changing slowly by comparing the TFR for any given year with the $C F R$ for the cohort that reaches its mean age at childbearing in this year (Ryder 1956; Sobotka 2003). If the 1960 birth cohort has a mean age at first birth of 25 years, for example, the $C F R$ for this cohort is compared with the TFR for 1985. To attenuate year-to-year fluctuations, TFRs may be averaged over a series of years.

To illustrate, Table 3 presents evidence for tempo distortion in the TFR of France during the last quarter of the $20^{\text {th }}$ century. The TFR was relatively stable during this period, with an average value of 1.80 children per woman. The completed fertility rate $(C F R)$ for the cohorts that were at prime childbearing ages during these periods was also nearly stable, but with an average value of 2.08 children per woman, 0.28 children per woman higher than the average total fertility rate. 
This disparity between period and cohort fertility is explained largely by a tempo distortion of the TFR resulting from the change in the period mean age at childbearing. This mean rose at an average annual rate of 0.125 years per year between 1975-80 and 1995-99 $\left(r_{p}=0.125\right)$. Since the constant fertility assumption is approximately valid, the $T F R$ implied by (2) is $C F R\left(1-r_{p}\right)=2.08(1-0.125)=1.82$ births per woman. This is very close to the observed average total fertility rate for the period, 1.80 children per woman. In this example, the translation formula (2) quite accurately estimates the tempo distortion due to rising mean age at childbearing.

In this illustration, the translation formula has been applied to births of all orders. In general, however, it is recommended that the translation formula be applied separately for births of each order, as illustrated in Bongaarts and Feeney (1998a).

\subsection{Empirical evidence supporting the theory: first births, first marriages, and deaths}

This section systematically applies and tests the Zeng-Land translation formula (2) using empirical data for first birth, first marriage, and death.

-First births. Figure 4 compares completed first birth cohort fertility for women born in $1960\left(C F R_{1}\right)$ and period first birth total fertility for 1980-89 $\left(T F R_{1}\right)$ for 15 European countries, the USA, and Japan. In most countries, the cohort level exceeds the period level. To show that this difference is due largely to tempo distortions, the translation equation (2) is rearranged as follows:

$$
\frac{T F R}{C F R}=1-r_{p} .
$$

This shows that, in a constant fertility population, there is a simple linear relationship between $T F R / C F R$ and $\left(1-r_{p}\right)$, so that if values of these two quantities for different countries are scatter plotted, the points will lie on a straight line with slope one that passes through the origin. Following Ryder, we refer to $\left(1-r_{p}\right)$ as the period distortion index.

To test the validity of this translation equation for first births, Figure 5 plots $T F R_{l} / C F R_{l}$ ratios (vertical axis) against the corresponding $\left(1-r_{p}\right)$ values (horizontal 
axis $)^{2}$ for the 17 countries represented in Figure 4 . There is a close correspondence between the data points for the 17 countries and the linear relation predicted by the translation equation. This confirms that tempo distortions of the $T F R_{1}$ are the main explanation for the difference between the $T F R_{I}$ and the $C F R_{l}$. We do not expect the observations for the different countries to fall exactly on the diagonal because the translation assumptions hold only approximately.

-First marriages. The same translation formula analysis may be applied to quantum and tempo measures of first marriage. The total first marriage rate is distorted by tempo effects in the same way that the total fertility rate is distorted by these effects. When the mean age at marriage is rising (falling), the same number of marriages occur over a longer (shorter) period and annual numbers of marriages are lower (higher) than they would have been in the absence of the change in the mean age. Most of the concepts and derivations developed for the analysis of fertility tempo apply to the analysis of "nuptiality tempo" as well. Recent studies by Goldstein (2003) and by Winkler-Dworak and Engelhardt (2004) provide examples of this application.

Figure 6 tests the translation equation for nuptiality. The ratio of the period to cohort quantum for first marriage $\left(T N R_{l} / C N R_{l}\right)$ is plotted against the distortion index $\left(1-r_{p}\right)$, with $r_{p}$ representing the rate of change in period mean age at first marriage. The diagonal line represents the relationship predicted by the translation equation. Most countries again fall close to the predicted values, confirming the existence of tempo distortions in first marriage rates.

-Deaths. We now extend the same translation formula analysis to the quantum and tempo measures of mortality based on rates of the 2nd kind. Since the cohort completed mortality rate necessarily equals one, the period-cohort ratio equals the $T M R$. The relationship predicted by the translation equation (4) is given by the diagonal line in Figure 7. (Following Bongaarts and Feeney $(2002,2003)$ the analysis of the quantum and tempo of mortality is limited to adult mortality above age 30 to ensure consistency with the constant shape assumption.) Figure 7 includes the resulting data points for seven countries (England and Wales, Italy, France, Norway, Switzerland, Sweden, and the US) for which the required historical data 
from 1900 to the present are available. As in the fertility and nuptiality analyses, the data points fall close to the line predicted by the translation equation, supporting both the validity of the translation equation and the existence of tempo distortions for adult mortality.

These analyses show that the tempo distortions established in the case of fertility apply to nuptiality and (adult) mortality as well when the period quantum measures for each event are calculated from rates of the 2 nd kind. They also show that the magnitude of tempo distortions may be substantial. Figures 5-7 show that average distortions of 10 percent are common during the 1980s and that distortions exceeding 20 percent occur for some countries for fertility, mortality, and in particular for nuptiality. The distortions are even larger in individual years. Bongaarts and Feeney (1998a), for example, estimate distortions in the TFR in the United States ranging from $+28 \%$ in 1948 to $-11 \%$ in 1975 .

\section{Correcting tempo distortions in quantum measures of the 2 nd kind}

Ryder's work established the existence of tempo distortions in the total fertility rate, but he did not propose specific, quantitative adjustments to counteract tempo distortions. This may be explained in part by his strong emphasis on the conceptual priority of cohort fertility measures and the corresponding tendency to denigrate period measures such as the TFR. The emphasis on cohorts probably influenced his focus on "translating" period measures to cohort measures as well, which diverted attention from the problem of adjusting period measures for tempo distortions.

Empirical research over the past three decades has demonstrated, however, that period influences on fertility are much more important than cohort influences. Brass (1974) concludes that cohort completed fertility reveals no significant feature that distinguishes it from time averages of period indexes. Pullum (1980) concludes that "temporal variations that cut across cohorts, such as economic cycles, appear to be more important than changes in those variables that distinguish cohorts, such as shared socializing experiences" (see also Page 1977). Foster's (1990) analysis of data for eight countries in Europe and North America arrives at a similar conclusion. In an authoritative review, Ní Bhrolcháin (1992) concludes that "of the two dimensions of calendar time- 
period and cohort - period is unambiguously the prime source of variation in fertility rates." Bongaarts and Feeney (2003) demonstrate that the same dominance of period effects exists for adult mortality rates in contemporary populations with high life expectancy. These findings provide the basis for the tempo adjustment procedure discussed next.

\subsection{Correcting tempo distortions in period quantum measures of fertility}

Bongaarts and Feeney (1998a) reformulated the issue of tempo distortions by posing the following counterfactual question: What would the total fertility rate have been in a particular year, other things being equal, if the mean age at childbearing had been constant during that year? Subject to a simplifying assumption on the pattern of fertility change, they show that the answer to this question is given by

$$
\operatorname{TFR}^{*}(t)=\frac{\operatorname{TFR}(t)}{1-r_{p}(t)},
$$

where $r_{p}$ denotes the rate of change in the period mean age at childbearing in year $t$. $T F R^{*}(t)$ is referred to as the tempo-adjusted TFR, and the tempo distortion in the observed TFR equals $T F R^{*}(t)-T F R(t)$.

Unlike the translation formulas (1) and (2), formula (6) involves only period measures. Another advantage of (6) is that it separates the issue of tempo distortion from the question of the relationship between period and cohort measures. The tempo-adjusted $T F R$ is not intended to estimate and need not equal the $C F R$ for any cohort. (However, as shown in Appendix A, the $C F R$ equals the weighted average of $T F R^{*}(t)$ values observed during the years in which the cohort reproduces.)

Formula (6) depends on the constant shape assumption, which may be stated in this way: the age schedule of fertility rates (of the 2nd kind) observed at any time can be transformed into the schedule observed at any other time by inflating or deflating and/or by shifting the schedule to higher or lower ages. This is equivalent to assuming that fertility is determined strictly by period effects. Because this is much less restrictive than the translation assumptions required for (2), the tempo adjustment equation (6) can therefore be applied much more widely. Recent studies by Kohler and Philipov (2001) and Zeng and Land (2001) confirm the validity of (6). 
Although equation (6) can be applied to births of all orders combined, superior results are obtained by applying the formula separately to each birth order component of the TFR, because the constant shape assumption is more valid for the fertility schedule at each order than for all orders combined (Bongaarts and Feeney 1998a). This disaggregation is particularly important in countries in which the overall $T F R$ is changing rapidly, for this will likely result in substantial changes in the weighting of the different birth order components.

Bongaarts and Feeney (1998a) and the follow-up work of Bongaarts (1999a, 1999b, 2002) have stimulated a number of criticisms, extensions, and elaborations. Van Imhoff and Keilman (2000) and Van Imhoff (2001) point out that the constant shape assumption does not hold exactly for the Netherlands and Norway during the second half of the 20th century. This issue is addressed by Zeng and Land (2001), who carried out a sensitivity analysis and concluded that "the Bongaarts-Feeney formula is not sensitive to temporal changes in the shape of the fertility schedules." Kohler and Philipov (2001), on the other hand, find that errors resulting from deviations from the assumption in Sweden were not insignificant and addressed this by proposing a procedure for calculating tempo-adjusted total fertility rates when the variance of the fertility schedule changes over time (see also Kohler and Ortega 2002a and 2002b). A number of past studies have applied the adjustment to fertility (Lesthaeghe and Willems, 1999; Smallwood, 2002; and Sobotka, 2003, 2004a, 2004b). Implications of fertility tempo effects for population growth are examined by Goldstein et al. (2003).

\subsection{Extension of tempo adjustments to nuptiality and mortality}

The Bongaarts-Feeney method can be extended to obtain estimates of tempoadjusted period quantum measures for life-cycle events other than fertility. Table 4 shows formulas for adjusted quantum and tempo for the total first birth rate, the total first marriage rate, and the total mortality rate. Tempo adjustments are effected by dividing observed event rates of the 2 nd kind by the period tempo distortion index, as in formula (6) above. As in Table 2, the formulas in the first row of the table define the tempo-adjusted total event rate $T E R *(t)$ and the tempo-adjusted mean age at 
event $M A E^{*}(t)$, with $d(a, t)$ denoting the age-specific rate of the 2 nd kind for any of the events shown.

The tempo-adjusted total mortality rate $T M R^{*}$

$$
\operatorname{TMR}^{*}(t)=\frac{T M R(t)}{1-r_{p}(t)}
$$

is of particular interest. Because $T M R^{*}(t)$ must equal one, it follows that

$$
\operatorname{TMR}(t)=1-r_{p}(t)
$$

This is a more general version of (4) because it allows $T M R(t)$ and $r_{p}(t)$ to vary over time. As noted, the results in Figure 7 confirm this relationship for mortality over age 30 .

The right hand column of Table 4 shows that tempo measures based on rates of the 2nd kind are not affected by tempo distortion (assuming the constant shape assumption holds). This is because the distortion index occurs in both the numerator and the denominator of the formula, and so cancels out. Empirical confirmation of this conclusion will be provided in a later section.

\subsection{Empirical application to first births, first marriages, and deaths}

Empirical estimates of tempo-adjusted quantum measures contain seemingly random year-to-year fluctuations. These are caused by sensitivity to small errors in $r_{p}(t)$ and by deviations from the constant shape assumption. To minimize these fluctuations, we plot five-year moving averages of $T E R^{*}(t)$ in place of annual values in Figures 8-10.

Figure 8 presents observed and tempo-adjusted total first birth fertility rates for the United States. ${ }^{3}$ The adjusted rates are lower than the observed rates during the 1950s and early 1960s, when the mean age at first birth was declining, and higher than the observed rates between 1975 and 1990, when the mean age at first birth was rising.

Figure 9 presents observed and adjusted total first marriage rates for France from 1960 to 1996. The adjusted rates are more plausible than the observed rates, because the adjusted rates are uniformly below one and because the tempo-adjusted 
total first marriage rate circa 1990 is 0.7 , which is approximately equal to the proportion ever marrying among cohorts born in the late 1960s.

Figure 10 gives the observed and adjusted total mortality rate (adult mortality only) for England and Wales. The adjusted rate fluctuates around the level of one, as it should. If the constant shape assumption holds perfectly, the tempo-adjusted TMRs would all equal one exactly, assuming no measurement error.

Figures 8-10 also include the corresponding quantum estimates for successive cohorts. Let $M(c)$ be the mean age at the event for the cohort born in year $c$. In Figure 8 the cohort quantum (i.e., the proportion ever having a first birth) for the cohort born in year $c=t-M(c)$ is plotted at time $t$. In Figure 9 this comparison of cohort and period quantum is made for the first marriage quantum and in Figure 10 for the quantum of mortality. In each of these comparisons, the (lagged) cohort quantum is close to the adjusted rate of the 2 nd kind, but the fit is not perfect. Perfect agreement between the cohort and adjusted period quantum is expected only when all the translation assumptions hold: the period and cohort quantum are constant, the period mean age is rising linearly, and the shape of the age pattern is constant. Since these assumptions do not hold exactly, the cohort quantum is not exactly equal to the adjusted total event rates, but the correspondence is good and clearly better than for the unadjusted rates. The observed differences between the cohort quantum and adjusted period quantum are due to three factors: deviation from the constant quantum assumption, deviation from the linear change assumption, and deviation from the constant shape assumption. The first two of these deviations do not cause errors in the adjusted quantum, which only requires the constant shape assumption. As a result even when the adjusted quantum is accurately estimated, it can differ from the lagged cohort quantum.

In the applications summarized in Figures 8-10 the adjustment procedure appears to work well. The obvious anomalies in unadjusted quantum measures noted earlier are all removed by the tempo adjustment, and the adjusted quantum is close to the lagged cohort quantum, even though the conditions for this comparison are not fully met.

Quantum and tempo measures of the 2nd kind are much more widely used in the analysis of fertility and nuptiality than measures of the 1st kind, because age-specific rates of the 2nd kind (adjusted and unadjusted) are easier to calculate and more widely 
available. A disadvantage of rates of the 2 nd kind is that they can be affected by compositional effects when the constant shape assumption does not hold (Kohler and Ortega 2004). It is therefore generally preferable to derive quantum and tempo measures from tempo-adjusted rates of the 1st kind if such rates are available.

\section{PART II: PERIOD QUANTUM AND TEMPO MEASURES OF THE 1st KIND}

The preceding sections of this study examined quantum and tempo measures of the 2nd kind as well as tempo effects in these measures. The present section will cover these same topics for rates of the 1st kind. These rates are used extensively in life table analyses of the quantum and tempo of life-cycle events. This discussion will be briefer because the main concepts have already been introduced and because data on measures of the 1st kind are not widely available except for mortality.

\section{Standard equations for quantum and tempo measures}

Table 5 presents equations for estimating quantum and tempo measures derived from rates of the 1st kind. Applying the general formulas in the first row to first birth, first marriage, and death produces quantum estimates $T F R_{1 L}(t), T N R_{1 L}(t)$, and $T M R_{L}(t)$ and tempo estimates $M A B_{1 L}(t), M A M_{1 L}(t)$, and $M A D_{L}(t)$. The subscript $\mathrm{L}$ signifies that these measures are based on the life table calculation using rates of the 1st kind. This distinguishes them from the corresponding measures based on rates of the 2 nd kind (see Table 2).

Period quantum based on rates of the 1st kind is defined as the proportion of persons ever experiencing the event in a hypothetical cohort subjected to these rates, as given by the standard life table calculation. The quantum of mortality $T M R_{L}(t)$ necessarily equals one because everyone eventually dies. The quantum of first birth $T F R_{1 L}(t)$ and the quantum of first marriage $T N R_{1 L}(t)$ are less than one because the rates from which they are calculated fall to zero at older ages.

The most widely used period tempo measure of the 1st kind is the life table mean age at death $M A D_{L}(t)$, which is usually referred to as life expectancy. With $T M R_{L}(t)=1$ the general tempo equation on the right in Table 5 simplifies to 


$$
M A D_{L}(t)=e_{0}(t)=\int_{0}^{\infty} \exp \left[-\int_{0}^{a} \mu(x, t) d x\right] d a,
$$

which is the conventional expression for the life table estimate of life expectancy at birth conventionally denoted $e_{0}(t)$.

Cohort measures based on rates of the 1 st kind are identical to the corresponding measures based on rates of the 2 nd kind, but period measures based on rates of the 1st kind do not in general equal the corresponding measures based on rates of the 2 nd kind. This will be illustrated in the following section.

\section{Tempo effects}

Tempo effects result from a depression or inflation in the numbers of events that occur in the numerators of rates. These effects therefore affect age-specific rates of the 1 st kind as well as rates of the 2 nd kind. Moreover, the effect is proportionally the same for age-specific rates of the 1st and 2nd kind and it is determined by the distortion index, which varies with the rate of change in the mean age at the event. This point was first made by Bongaarts and Feeney (1998a) and subsequently by Kohler and Ortega (2002a, 2002b) in their analysis of tempo effects in fertility rates of the 1st kind.

Tempo distortions of measures of the 1st kind are generally less noticeable than distortions of measures of the 2 nd kind. Tempo distortions in quantum measures based on rates of the 2nd kind are obvious, for example, whenever these measures exceed one. This cannot happen for quantum measures based on rates of the 1st kind because the life table calculations used necessarily lead to values less than or equal to one. The absence of obvious anomalies in these measures does not mean that they are free of tempo distortions, however.

Tempo distortions in period quantum measures of the 1 st kind are well established and uncontroversial in fertility (Sobotka 2003, 2004a,b; Kohler and Ortega, 2002a, 2002b) and in nuptiality (Goldstein, 2003; Winkler-Dworak and Engelhardt, 2004). Mortality rates of the 1 st kind also contain tempo effects, but the period mortality quantum derived from them always equals one because these rates rise with age. 
Tempo distortions in period tempo measures of the 1st kind are much less established and we will therefore examine this issue in more detail. The theoretical basis for the existence of such an effect is that tempo measures are derived from the same rates that produce quantum measures. If the quantum measures contain tempo effects, then the same should be true for tempo measures. As noted earlier, a rising mean age depresses rates of the 1st and 2nd kind and hence leads to downward distortions of quantum measures of both kinds. When these depressed rates are then used in a life table to obtain a mean age, this mean will contain an upward distortion. One would therefore expect the mean age of the 1st kind to be higher than the mean of the 2nd kind when the mean is rising. Moreover, since means of the 2nd kind are not distorted, the difference between the means of the 1st and 2nd kind equals the tempo effect (assuming the constant shape assumption holds).

\subsection{Tempo distortions in the period mean age at first birth}

Figures 11-13 compare mean ages at first birth of the 1st and 2nd kind in the Czech Republic, the Netherlands, and Spain. In all three countries these means have risen, but the means of the 1 st kind are higher than those of the 2nd kind. The difference between these means is as expected from the operation of the tempo effect. According to the theoretical argument presented earlier, the mean of the 1st kind is distorted because the numerators of rates of the first kind contain tempo effects. Means of the 2nd kind are not distorted because tempo effects in the numerators of rates of the 2nd kind are offset by tempo effects in their denominators. As a result, in years when the mean age at first birth is rising, tempo effects raise the mean of the 1st kind above the mean of the 2 nd kind. Note that these means are nearly equal to one another in the Czech Republic before 1990 and in the Netherlands after 1997. These are periods when the mean age at first birth did not change and as result there are no tempo effects.

In support of the argument that the mean of the 2nd kind is not distorted, Figures 11-13 include the mean ages at first birth of successive cohorts. The cohort mean age at first birth $M(c)$ for a cohort born in year $c=t-M(c)$ is plotted at time $t$. This cohort mean age is close to the mean age of the 2nd kind in the Czech Republic and in Spain and falls between the means of the 1st and 2nd kind in the Netherlands. Theoretical work by 
Rodriguez (2005) and Goldstein (2005) has proved that $M(c)$ equals the mean of the 2nd kind when the translation assumptions hold. Since these assumptions do not hold exactly, $M(c)$ is not exactly equal to the observed mean of the 2nd kind, but the correspondence is good and clearly better than for means of the 1st kind.

\subsection{Tempo distortions in the period mean age at death (i.e., in life expectancy)}

Figures 14-16 compare the period mean ages at death of the 1st and 2nd kind for Denmark, England and Wales, and Sweden (as before mortality under age 30 is assumed to be absent). The results are broadly similar to those for first birth: the means have risen over time and the mean of the 1st kind (i.e., period life expectancy) exceeds the mean of the 2nd kind. The difference between the two means again equals the tempo effect. In addition, the lagged cohort mean age at death is close to the mean age of the 2 nd kind, which is as expected in a population in which the translation assumptions hold for adult death rates.

In sum, our conclusion that the period mean age at a life-cycle event calculated with standard life table methods is distorted by tempo effects is based on and supported by the following findings:

1) The theoretical analysis of the preceding sections shows that a rising mean age at an event depresses age-specific period event rates of the 1st kind. These depressed rates in turn inflate calculated period mean ages of the 1st kind. Similarly, a falling mean age at an event inflates age-specific event rates and depresses mean ages of the 1st kind obtained with standard life table methods.

2) The observed period mean age of the 1st kind exceeds the period mean age of the 2nd kind in populations in which the mean age is rising. Figures 11-13 demonstrate this for first birth and Figures 14-16 for death. This difference is due to a tempo distortion in the mean of the 1st kind, because, as noted, the mean age of the 2 nd kind is not distorted.

3) The differences between the period means of the 1st and 2nd kind (i.e., the tempo effect) disappear when the mean age stops rising. This is evident for means of the first birth in the Czech Republic before 1990 in Figure 11 and for the Netherlands after 1997 in Figure 12, and for the mean ages at death in Denmark in the mid-1990s in Figure 
14. These results are of course as expected because when there is no change in the tempo of an event there should be no tempo effect.

4) The cohort mean age for a cohort born in year $c=t-M(c)$ is close to the period mean age of the 2nd kind. This is illustrated in Figures 11-16.

In addition, as shown below, the tempo-adjusted mean of the 1st kind is close to the observed mean of the 2nd kind.

\subsection{A simple example of the mortality tempo effect}

Since a tempo effect in life expectancy is a new and complex concept, we present a simple hypothetical example to demonstrate how the mortality tempo effect operates. Consider a stationary population with a life expectancy at birth of 70 years. Suppose further that a "life extension" pill is invented that defers the death of any person who consumes it by 3 months. If everyone in the population takes this pill on January 1 of year $T$, there will be no deaths during the first three months of the year. The number of deaths during this year is 25 percent lower than it would have been without the pill, and the mean age at death is 70.25 years rather than 70 years. Since the pill's effect is the same at all ages, the level of the force of mortality function is also reduced by 25 percent, and the age to which each value of the function is attached increases by 0.25 years. This change in the force of mortality function causes life expectancy at birth as conventionally calculated to rise to nearly 73 years for year $T$ (see Figure 17).

In the following year, $T+1$, the number of deaths and the force of mortality function rise to the level observed before year $T$, but with values shifted forward to older ages by 0.25 years. Life expectancy at birth as conventionally calculated, having risen from 70 years prior to year $T$ to nearly 73 years during year $T$, falls back to 70.25 years, as shown in Figure 17. This rise and fall in life expectancy at birth as conventionally calculated is a tempo distortion because it is at variance with the known trend in the mean length of life. Distortion of this kind occurs whenever the mean age at death changes.

This illustration demonstrates the operation of the tempo effect that distorts life expectancy under highly simplified hypothetical conditions. The example can be made more realistic in several ways. First, the life-extending pill can be taken year after year from year $T$ onward. In that case, life expectancy will be distorted not only in year $T$ but in every subsequent year as well. The mean age at death will rise over time and the 
observed life expectancy will continuously exceed the rising mean age at death due to the tempo effect. Second, the strength of the pill can vary from year to year, thus yielding tempo effects that also vary from year to year. Finally, the intervals between pill taking can be shortened while correspondingly reducing the pill's life-extending effect so that the annual "dose" remains the same. As the pill frequency rises and the pill size declines, in the limit the mortality pattern in the hypothetical illustration approaches a real adult mortality pattern in a population in which the fixed-shape assumption holds. Subject to this assumption, improvements in adult mortality can therefore be seen as resulting from the continuous provision of increments to life to all living individuals in every period, with the increments varying over time.

A similar illustration of the impact of a hypothetical "pill" to delay a birth could easily be provided, and it would show a similar tempo distortion of the mean age at birth calculated with a conventional life table.

\section{Correcting tempo distortions}

The method for removing tempo effects from rates of the 1st kind is the same as for rates of the 2 nd kind: division of the observed rates by the distortion index. Table 6 presents general equations for adjustment as well as applications to first births, first marriages, and deaths. Subject to a constant shape assumption, ${ }^{4}$ tempo distortions are removed by dividing the rates in the formulas by $1-r_{p}(t)$, where $r_{p}(t)$ denotes the rate of change in the period mean age of the event.

Observe that, for period measures of the 1st kind, tempo distortions occur for tempo as well as for quantum measures. This is in striking contrast to period measures of the 2nd kind, for which tempo measures are unaffected by tempo distortions if the constant shape assumption holds (because distortions in the numerator and denominator cancel out; see Table 4, right column). For this reason, tempo adjustments are best made using the rate of change in the mean age of the 2 nd kind to calculate the distortion index. Note that the procedure used here to make tempo adjustments is different from the one used by Kohler and Ortega (2002a), who rely on the rate of change in the mean age of the 1 st kind. We believe that our approach is more accurate.

To illustrate the correction for tempo distortion in tempo measures, we apply the above procedure to mortality, to obtain a tempo-adjusted life expectancy (mean of the 1st 
kind). It follows that calculated life expectancy at birth may be adjusted for the tempo distortion by dividing the observed age-specific death rates by $1-r_{p}(t)$ and by using these adjusted age-specific rates in the life table calculation (provided the constant shape assumption holds). This result is equivalent to substituting $T E R_{L}^{*}(t)=T M R_{L}^{*}(t)=1$ in the tempo equation in the top right cell of Table 6, giving the following tempo-adjusted life expectancy at birth

$$
M A D_{L}^{*}(t)=e_{0}^{*}(t)=\int_{0}^{\infty} \exp \left\{-\int_{0}^{a} \frac{\mu(x, t)}{1-r_{p}(t)} d x\right\} d a,
$$

where $r_{p}(t)$ denotes the rate of change in the period mean age at death $M A D(t)$.

Because $1-r_{p}(t)=T M R(t)$ (see formula (8) above), (10) may also be written as

$$
M A D_{L}^{*}(t)=e_{0}^{*}(t)=\int_{0}^{\infty} \exp \left\{-\int_{0}^{a} \frac{\mu(x, t)}{T M R(t)} d x\right\} d a,
$$

which gives more stable results in empirical application. The tempo distortion in the conventional life expectancy at birth equals the difference between $M A D_{L}(t)$ and $M A D_{L}^{*}(t)$.

Bongaarts and Feeney (2003) prove that the tempo-adjusted life expectancy at birth given by (10) or (11) equals the mean age at death calculated from rates of the 2 nd kind (i.e., $M A D(t)$ in Table 2),

$$
M A D_{L}^{*}(t)=M A D(t),
$$

provided the constant shape assumption holds.

Table 7 shows empirical estimates for three alternative estimates of the mean age at death (average of annual values for 1970-1990, no mortality under age 30) for females in Denmark, England and Wales, and Sweden ${ }^{5}$ :

$M A D(t)$, derived from rates of the 2nd kind (not distorted)

$M A D_{L}(t)=e_{0}(t)$, derived from rates of the 1st kind (distorted)

$M A D_{L}^{*}(t)$, derived from tempo-adjusted rates of the 1st kind (distortion corrected)

These results confirm that $M A D(t)$ and $M A D_{L}^{*}(t)$ have nearly the same value as predicted by (12). Table 7 also documents substantial tempo effects in the conventionally 
calculated life expectancy, $e_{0}(t)=M A D_{L}(t)$. The upward distortions in female life expectancy at birth for 1970-1990 are estimated at 1.5 years in Denmark, 1.4 years in England and Wales, and 1.9 years in Sweden. Using an indirect method Bongaarts and Feeney (2002) estimate a distortion of 3.3 years for Japan.

The preceding analysis has demonstrated that tempo-adjusted mortality tempo measures of the 1 st and 2 nd kind are equal under the constant shape assumption. As shown in Appendix B, this equality holds in general for both tempo-adjusted quantum and tempo measures for any life-cycle event whenever the observed proportion ever having experienced the event, $p(t)$, maintains its shape over time as the mean age at the event rises or falls over time. This condition holds approximately for adult mortality in contemporary low-mortality populations (Bongaarts and Feeney 2002, 2003).

\section{Conclusion}

Demographers have developed a number of widely used methods to estimate the quantum and tempo of life-cycle events. The level of fertility, for example, is usually measured by the total fertility rate and the level of mortality by the life expectancy at birth. The wide availability, ease of interpretation, and up-to-date nature of these conventional period indicators have led to neglect of some of their deficiencies. Most analysts are aware of inaccuracies due to sampling error and incomplete vital registration, but they often neglect the pervasive influence of tempo distortions of many period indicators of life-cycle events.

Tempo distortions in period fertility measures were discovered more than half a century ago and are generally acknowledged. The postwar baby boom in the United States, for example, was due in part to a decline in the age at childbearing, and the recent low total fertility rates in many developed countries are in part due to delays in childbearing. This study argues that similar tempo distortions can occur in period measures of other life-cycle events, including marriage and death. This is the case even for measures derived from period life tables such as life expectancy at birth. These distortions are not generally recognized and are rarely if ever taken account of in empirical analysis.

Comparisons of period and cohort measures indicate that tempo distortions can be substantial in size. Distortions in the total fertility, marriage, and mortality 
rates of more than $10 \%$ were common during the 1980 s. Using distorted age-specific death rates in a mortality life table leads to distorted estimates of life expectancy (typically exaggerated by 1-2 years).

The adjustment method proposed earlier by Bongaarts and Feeney is shown both by theoretical argument and by empirical example to be an effective, if approximate, solution to the problem of adjusting tempo and quantum measures for life-cycle events. Although this approach makes a simplifying assumption about changes over time in the age patterns of event rates, the results appear generally robust to deviations from this assumption.

The adjusted period tempo and quantum measures should be interpreted as variants of their conventional counterparts. The total fertility rate, for example, is defined as the average number of births for a hypothetical cohort of women subjected throughout life to the age-specific birth rates observed in a given year. This is a hypothetical rate because no actual cohort will experience these observed period birth rates. The tempoadjusted total fertility rate is a similar hypothetical measure, but one that corrects for distortions caused by year-to-year tempo changes. Neither the observed nor adjusted total fertility rate attempts to estimate the fertility rate of any actual cohort, nor do they attempt any prediction of future fertility. The goal of the tempo adjustment is simply to provide period quantum and tempo measures that are free of the tempo distortions in conventional measures.

Distorted views of past levels and trends in the quantum and tempo of lifecycle events may lead to misleading projections and to the adoption of sub-optimal social and health policies. It is therefore desirable for analysts to understand the strengths and weaknesses of period indicators of life-cycle events and to recognize and correct tempo distortions. 


\section{Appendix A : Relationship between the completed fertility rate and the weighted average of tempo-adjusted period total fertility rates}

Let age-specific fertility rates at time $t$ and age $a$ be denoted $d(a, t)$. The total fertility rate equals

$$
\operatorname{TFR}(t)=\int d(a, t) d a
$$

The distribution of fertility by age at time $t$ is denoted $f(a, t)$ :

$$
f(a, t)=\frac{d(a, t)}{\operatorname{TFR}(t)}
$$

so that $\int f(a, t) d a=1$ and $d(a, t)=\operatorname{TFR}(t) f(a, t)$.

The completed fertility rate for the cohort born in year $t_{0}$ equals

$$
C F R\left(t_{0}\right)=\int d\left(a, t_{0}+a\right) d a=\int \operatorname{TFR}\left(t_{0}+a\right) f\left(a, t_{0}+a\right) d a
$$

rearranging (6) yields

$$
\operatorname{TFR}(t)=\left[1-r_{p}(t)\right] T F R *(t)
$$

and substitution of (4a) in (3a) gives

$$
\begin{aligned}
C F R\left(t_{0}\right) & =\int T F R *\left(t_{0}+a\right)\left[1-r_{p}\left(t_{0}+a\right)\right] f\left(a, t_{0}+a\right) d a \\
& =\int T F R *\left(t_{0}+a\right) v\left(a, t_{0}\right) d a
\end{aligned}
$$

where $v\left(a, t_{0}\right)=\left[1-r_{p}\left(t_{0}+a\right)\right] f\left(a, t_{0}+a\right)$.

The weighted average of $T F R^{*}(t)$ is defined as

$$
\overline{\operatorname{TFR}}\left(t_{0}\right)=\frac{\int T F R *\left(t_{0}+a\right) v\left(a, t_{0}\right) d a}{\int v\left(a, t_{0}\right) d a}=\int \operatorname{TFR} *\left(t_{0}+a\right) w\left(a, t_{0}\right) d a
$$

where $w\left(a, t_{0}\right)=v\left(a, t_{0}\right) / \int v\left(a, t_{0}\right) d a$

It follows from (5a) and (6a) that

$$
C F R\left(t_{0}\right)=\overline{T F R}\left(t_{0}\right) \int v\left(a, t_{0}\right) d a
$$

Equations 5a, 6a, and 7a hold in general and do not require any simplifying assumptions.

However, it can be shown that $\int v\left(a, t_{0}\right) d a=1$ and $w\left(a, t_{0}\right)=v\left(a, t_{0}\right)$ when the constant shape assumption holds. In that case $C F R\left(t_{0}\right)=\overline{T F R}\left(t_{0}\right)$. 


\section{Appendix B: Comparison of measures of the 1st and 2nd kind}

If age-specific rates change without conditions, then period quantum and tempo measures of the 1st kind generally differ from measures of the 2 nd kind. We will now demonstrate that this difference between measures of the 1st and 2nd kind disappears if the tempo effect is removed and if the shape of the proportion ever having experienced the event remains invariant as the mean age at the event changes.

Holding the shape of $p(t)$ constant implies

$$
p(a, t)=p(a-S(t), 0) \text { for } a \geq S(t) \text { and } p(a, t)=1 \text { for } a<S(t)
$$

where $S(t)$ is equal to the amount of the shift since $t=0$. As shown by Bongaarts and Feeney $(2002,2003)$ (1b) implies that

$$
d(a, t)=\left[1-r_{p}(t)\right] \frac{-\partial p(a, t)}{\partial a}
$$

and $\mu(a, t)=\left[1-r_{p}(t)\right] \frac{\frac{-\partial p(a, t)}{\partial a}}{p(a, t)}$

Let the tempo-adjusted versions of $\mu(a, t)$ and $d(a, t)$ be denoted $\mu^{*}(a, t)$ and $d *(a, t)$ respectively; then

$$
\begin{aligned}
& d^{*}(a, t)=\frac{d(a, t)}{1-r_{p}(t)}=\frac{-\partial p(a, t)}{\partial a} \\
& \mu^{*}(a, t)=\frac{d^{*}(a, t)}{p(a, t)}=\frac{\frac{-\partial p(a, t)}{\partial a}}{p(a, t)}
\end{aligned}
$$

It follows from (4b) and (5b) that

$$
p(a, t)=1-\int_{0}^{a} d *(x, t) d x=1-\exp \left[-\int_{0}^{a} \mu *(x, t) d x\right]
$$

Rearranging (6b) and integrating to $m$, the highest age at which the event is observed, gives

$$
\exp \left[-\int_{0}^{m} \mu^{*}(x) d x\right] p(a)=1-p(m, t)
$$


and

$$
\int_{0}^{m} d *(x) d x=1-p(m, t)
$$

Substitution of (7b) and (8b) in the equations for tempo-adjusted quantum of the 1 st and 2nd kind (from Tables 4 and 6 respectively) shows that the tempo-adjusted quantum of the 1 st kind

$$
T E R_{L}^{*}(t)=1-\exp \left\{-\int_{0}^{m} \frac{\mu(a, t)}{1-r_{p}(t)} d a\right\}=1-\exp \left\{-\int_{0}^{m} \mu *(a, t) d a\right\}=1-p(m, t)
$$

equals the tempo-adjusted quantum of the 2 nd kind

$$
\operatorname{TER}^{*}(t)=\int_{0}^{m} \frac{d(a, t)}{1-r_{p}(t)} d a=\int_{0}^{m} d *(a, t) d a=1-p(m, t)
$$

Similarly, the tempo-adjusted mean age of the 1st kind

$$
\begin{aligned}
M A E_{L}^{*}(t) & =\frac{1}{T E R_{L}^{*}(t)} \int_{0}^{m}\left\{\exp \left[-\int_{0}^{a} \frac{\mu(x, t)}{1-r_{p}(t)} d x\right]+T E R_{L}^{*}(t)-1\right\} d a \\
& =\frac{1}{1-p(m, t)} \int_{0}^{m}\left\{\exp \left[-\int_{0}^{a} \mu^{*}(x, t) d x\right]-p(m, t)\right\} d a \\
& =\frac{1}{1-p(m, t)} \int_{0}^{m}\{p(a, t)-p(m, t)\} d a
\end{aligned}
$$

equals the tempo-adjusted mean age of the second kind

$$
\begin{aligned}
\operatorname{MAE}^{*}(t) & =\frac{1}{T E R^{*}(t)} \int_{0}^{m} \frac{a d(a, t)}{1-r_{p}(t)} d a \\
& =\frac{1}{1-p(m, t)} \int_{0}^{m} a d^{*}(a, t) d a \\
& =\frac{1}{1-p(m, t)} \int_{0}^{m} a \frac{\partial p(a, t)}{\partial a} d a= \\
& =\frac{1}{1-p(m, t)} \int_{0}^{m}[p(a, t)-p(m, t)] d a
\end{aligned}
$$

Whenever (1b) holds, tempo-adjusted quantum and tempo measures of the 1 st and 2nd kind are equal to one another. 


\section{References}

Bongaarts, John. 1999a. "The fertility impact of changes in the timing of childbearing in the developing world," Population Studies 53: 277-289.

Bongaarts, John. 1999b. "Fertility decline in the developed world: Where will it end?" American Economic Review 89(2): 256-260.

Bongaarts, John. 2002. "The end of the fertility transition in the developed world," Population and Development Review 28(3): 419-433.

Bongaarts, John and Griffith Feeney. 1998a. "On the quantum and tempo of fertility," Population and Development Review 24(2): 271-291.

Bongaarts, John and Griffith Feeney. 1998b. "On the quantum and tempo of fertility: A reply," Population and Development Review 26(3): 560-564.

Bongaarts, John, and Griffith Feeney. 2002. "How long do we live?" Population and Development Review 28(1): 13-29.

Bongaarts, John, and Griffith Feeney. 2003. "Estimating mean lifetime," Proceedings of the National Academy of Sciences. 100 (23): 13127-13133.

Brass, W. 1974. "Perspectives in population prediction: Illustrated by the statistics of England and Wales," Journal of the Royal Statistical Society A 137: 55-72.

Brouard, N. 1986. "Structure et dynamique des populations. La pyramide des années a vivre, aspects nationaux et exemples régionaux," Espace-PopulationsSocietes (2): 14-15, 157-68.

Council of Europe. 2002. Recent Demographic Developments in Europe 2002. Strasbourg: Council of Europe Publishing.

Feeney, Griffith, and Jingyuan Yu. 1987. "Period parity progression measures of fertility in China," Population Studies 41: 77-102.

Feeney, Griffith, Feng Wang, Mingkun Zhou, and Baoyu Xiao. 1989. "Recent fertility dynamics in China: Results from the 1987 One Percent Population Survey," Population and Development Review 15: 297-322. 
Foster, Andrew. 1990. "Cohort analysis and demographic translation: A comparative study of recent trends in age specific fertility rates from Europe and North America," Population Studies 44: 287-315.

Goldstein, Joshua R. 2003. "Late but not never: The tempo and quantum of first marriage in France," Submitted for publication.

Goldstein, Joshua. 2005. "Found in translation?" Demographic Research. (forthcoming)

Goldstein, Joshua, Wolfgang Lutz, and Sergei Scherbov. 2003. "Long-term population decline in Europe: The relative importance of tempo effects and generational length," Population and Development Review 29(4): 699-707.

Guillot, Michel. 2003. "The cross-sectional average length of life (CAL): A crosssectional mortality measure that reflects the experience of cohorts," Population Studies 57(1): 41-54.

Hajnal, J. 1947. "The analysis of birth statistics in the light of the recent international recovery of the birth-rate," Population Studies 1: 137-164.

Hajnal, J. 1953. "Age at marriage and proportions marrying," Population Studies 7: $111-136$.

Hamilton, B. E., P. D. Sutton, and S. J. Ventura. 2003. "Revised birth and fertility rates for the 1990s and new rates for Hispanic populations, 2000 and 2001: United States," National Vital Statistics Reports 51: 1-96.

Henry, L. 1972. Demographie: Analyse et Modeles. Paris: Librairie Larousse.

Henry, L. 1980. Fertility of Marriages: A New Method of Measurement, Population Studies Translation Series, No. 3. New York: United Nations. Originally published 1953.

Heuser, Robert L. 1976. Fertility Tables for Birth Cohorts by Color: United States 1917-73. DHEW Publication No. (HRA) 76-1152. Rockville, MD: National Center for Health Statistics.

Hoem, Britta and Jan M. Hoem. 1999. "Fertility trends in Sweden up to 1996," Population Bulletin (United Nations) 40/41: 318-333. 
Human Mortality Database. 2005. Data downloaded from www. mortality.org in July 2005.

Keilman, Nico. 1994. "Translation formulae for non-repeatable events," Population Studies 48(2): 341-357.

Kim, Y.J. and R. Schoen. 2000. "On the quantum and tempo of fertility: Limits to the Bongaarts-Feeney adjustment," Population and Development Review 26(3): 554-559.

Kohler, H.P. and M. Philipov. 2001. "Variance effects in the Bongaarts-Feeney formula," Demography 38: 1-16.

Kohler, H.P. and J.A.Ortega. 2002a. "Tempo-adjusted period parity progression measures, fertility postponement and completed cohort fertility," Demographic Research 6: 92-144. www.demographic-research.org

Kohler, H.P. and J.A.Ortega. 2002b. "Tempo-adjusted period parity progression measures: Assessing the implications of delayed childbearing for cohort fertility in Sweden, the Netherlands and Spain," Demographic Research 6: 146-190. www.demographic-research.org

Kohler, H.-P. and J. A. Ortega. 2004. "Old insights and new approaches: Fertility analysis and tempo adjustment in the age-parity model," Vienna Yearbook of Population Research 2: 55-87.

Lesthaeghe, Ron and Paul Willems. 1999. "Is low fertility a temporary phenomenon in the European Union?" Population and Development Review 25(2): 211-228.

Ní Bhrolcháin, Máire. 1987. "Period parity progression ratios and birth intervals in England and Wales, 1941-1971: A synthetic life table analysis," Population Studies 41: 103-125.

Ní Bhrolcháin, Máire. 1992. "Period paramount? A critique of the cohort approach to fertility," Population and Development Review 18: 599-629.

Page, H. J. 1977. "Patterns underlying fertility schedules: A decomposition by both age and marriage duration," Population Studies 30: 85-106. 
Philipov, D., and H-P. Kohler. 2001. "Tempo effects in the fertility decline in Eastern Europe: Evidence from Bulgaria, the Czech Republic, Hungary, Poland and Russia," European Journal of Population 17(1): 37-60.

Preston, Samuel H., Patrick Heuveline, and Michel Guillot. 2001. Demography: Measuring and Modeling Population Processes. Malden, MA: Blackwell.

Pullum, T.W. 1980. "Separating age, period and cohort effects in white US fertility, 1920-70," Social Science Research 9: 225-244.

Rallu, Jean-Louis, and Laurent Toulemon. 1994. "Period fertility measures: The construction of different indices and their application to France, 1946-89," Population: An English Selection 6: 59-94.

Rodriguez, German. 2005. "Demographic Translation and Tempo Effects: An Accelerated Failure Time Perspective," Demographic Research . (forthcoming)

Ryder, Norman B. 1956. "Problems of trend determination during a transition in fertility," Milbank Memorial Fund Quarterly 34: 5-21.

Ryder, Norman B. 1959. "An appraisal of fertility trends in the United States," in Thirty Years of Research in Human Fertility: Retrospect and Prospect. New York: Milbank Memorial Fund, pp. 38-49.

Ryder, Norman B. 1964. "The process of demographic translation," Demography 1: $74-82$.

Ryder, Norman B. 1980. "Components of temporal variations in American fertility," in R.W. Hiorns (ed.), Demographic Patterns in Developed Societies, London: Taylor \& Francis, pp. 15-54.

Ryder, Norman B. 1983. "Cohort and period measures of changing fertility," in Rodolfo A. Bulatao and Ronald D. Lee (eds.), Determinants of Fertility in Developing Countries. New York: Academic Press, Vol. 2, pp. 737-756.

Ryder, Norman B. 1986. "Observations on the history of cohort fertility in the United States," Population and Development Review 12: 617-643.

Sardon, Jean Paul. 1993. "Un indicateur conjoncturel de mortalité : l'exemple de la France," Population 48(2): 347-368. 
Sardon, Jean Paul. 1994. "A period measure of mortality. The example of France," Population: An English Selection, 6: 131-150.

Sardon, Jean Paul. 2000 "The demographic situation of Europe and the developed countries overseas," Population: An English Selection, 12: 293-328.

Sardon, Jean Paul. 2004a. Unpublished special tabulations from data bank of Observatoire Démographique Européen provided to John Bongaarts on January 15 .

Sardon, Jean Paul. 2004b "Recent demographic trends in the developed countries," Population: An English Selection 59 (2): 263-314.

Sato, Ryuzaburo. 2001. Unpublished special tabulations from Japanese vital registration data provided to John Bongaarts.

Shryock, Henry S. and Jacob S. Siegel. 1973. The Methods and Materials of Demography. US Bureau of the Census. Washington, DC: US Government Printing Office.

Smallwood, S. 2002. "The effects of changes in timing of childbearing on measuring fertility in England and Wales" Population Trends, No. 109: 36-45.

Sobotka, T. 2003. "Tempo-quantum and period-cohort interplay in fertility changes in Europe. Evidence from the Czech Republic, Italy, the Netherlands and Sweden," Demographic Research 8: 152-214.

Sobotka, T. 2004a. Postponement of childbearing and low fertility in Europe. Doctoral thesis, University of Groningen. Dutch University Press, Amsterdam, xiv +298 pp.

Sobotka, Tomás. 2004b. "Is lowest-low fertility in Europe explained by the postponement of childbearing?" Population and Development Review 30(2): 195-220.

Van Imhoff, Evert. 2001. "On the impossibility of infering cohort fertility measures from period fertility measures," Demographic Research 5(2): 23-60.

Van Imhoff, Evert, and Nico Keilman. 2000. "On the quantum and tempo of fertility: Comment," Population and Development Review 26(3): 549-553. 
Whelpton, Pascal K. 1954. Cohort Fertility: Native White Women in the United States. Princeton, NJ: Princeton University Press. [Reissued 1973, Port Washington, NY: Kennikat Press.]

Winkler-Dworak, Maria and Henriette Engelhardt. 2004. "On the tempo and quantum of first marriages in Austria, Germany, and Switzerland," Demographic Research 10(9): 231-263.

Zeng, Yi and K.C. Land. 2001. "A sensitivity analysis of the Bongaarts-Feeney method for adjusting bias in observed period total fertility rates," Demography 38: 17-28.

Zeng, Yi and K.C. Land. 2002. "Adjusting period tempo changes with an extension of Ryder's basic translation equation," Demography 39: 269-285. 


\begin{tabular}{|c|c|c|}
\hline Event & $\begin{array}{c}\text { Rates of the 1st kind } \\
\text { (Occurrence-Exposure Rates) }\end{array}$ & $\begin{array}{c}\text { Rates of the 2nd kind } \\
\text { (Frequencies) }\end{array}$ \\
\hline \multirow{2}{*}{$\begin{array}{l}\text { First } \\
\text { Birth }\end{array}$} & 1 st births at age $a$ and time $t$ & 1 st births at age $a$ and time $t$ \\
\hline & Childless women age $a$ at time $t$ & All women age $a$ at time $t$ \\
\hline \multirow{2}{*}{$\begin{array}{l}\text { First } \\
\text { Marriage }\end{array}$} & 1st marriages at age $a$ and time $t$ & 1 st marriages at age $a$ and time $t$ \\
\hline & $\overline{\text { Never-married women at age } a \text { and time } t}$ & All women age $a$ at time $t$ \\
\hline \multirow{2}{*}{ Death } & Deaths at age $a$ and time $t$ & Deaths at age a and time $\mathrm{t}$ \\
\hline & Persons living at age $a$ and time $t$ & All persons born at time $\mathrm{t}-\mathrm{a}$ \\
\hline
\end{tabular}

\begin{tabular}{|l|l|l|}
\hline $\begin{array}{l}\text { Table 2. Period measures of quantum and tempo based on rates of the 2nd kind for } \\
\text { first birth, first marriage, and death }\end{array}$ \\
\hline \multicolumn{1}{|c|}{ Period Quantum } & \multicolumn{1}{c|}{ Period Tempo } \\
\hline $\begin{array}{l}\text { General } \\
\text { Formula }\end{array}$ & $\begin{array}{c}\text { Total event rate, } T E R(t) \\
T E R(t)=\int_{0}^{\infty} d(a, t) d a\end{array}$ & $\begin{array}{l}\text { Mean age at event, } M A E(t) \\
M A E(t)=\frac{1}{T E R(t)} \int_{0}^{\infty} a d(a, t) d a\end{array}$ \\
\hline $\begin{array}{l}\text { First } \\
\text { Birth }\end{array}$ & Total fertility rate, order $1, T F R_{l}(t)$ & Mean age at 1 st birth, $M A B_{1}(t)$ \\
\hline $\begin{array}{l}\text { First } \\
\text { Marriage }\end{array}$ & Total $1^{\text {st }}$ marriage rate, $T N R_{l}(t)$ & Mean age at 1 st marriage, $M A M_{l}(t)$ \\
\hline Death & Total mortality rate, $T M R(t)$ & $\begin{array}{l}\text { Mean age at death (birth cohort } \\
\text { normalized), } M A D(t)\end{array}$ \\
\hline
\end{tabular}




\begin{tabular}{|c|c|c|c|}
\hline Period & $\begin{array}{l}T F R \text { (births } \\
\text { per woman) }\end{array}$ & $\begin{array}{l}\text { CFR (births per } \\
\text { woman) }\end{array}$ & $\begin{array}{l}\text { Mean age at child- } \\
\text { bearing (years) }\end{array}$ \\
\hline $1975-79$ & 1.86 & $2.11(1950)^{\mathrm{a}}$ & 26.6 \\
\hline $1980-84$ & 1.88 & $2.13(1955)$ & 27.1 \\
\hline $1985-89$ & 1.81 & $2.10(1960)$ & 27.9 \\
\hline $1990-94$ & 1.72 & $1.99(1965)$ & 28.5 \\
\hline 1995-99 & 1.74 & & 29.1 \\
\hline Average & 1.80 & 2.08 & \\
\hline
\end{tabular}

Source: Council of Europe 2002 a. Year of birth of cohort in parentheses

\begin{tabular}{|l|l|l|}
\hline $\begin{array}{l}\text { Table 4: Adjustments for tempo distortions in period quantum and tempo } \\
\text { measures based on rates of the 2nd kind }\end{array}$ \\
\hline Event & \multicolumn{1}{|c|}{$\begin{array}{c}\text { Adjusted Quantum } \\
\text { (total event rate) }\end{array}$} & \multicolumn{1}{c|}{$\begin{array}{c}\text { Adjusted Tempo } \\
\text { (mean age at event) }\end{array}$} \\
\hline General & $T E R^{*}(t)=\int_{0}^{\infty} \frac{d(a, t)}{1-r_{p}(t)} d a=\frac{T E R(t)}{1-r_{p}(t)}$ & $M A E^{*}(t)=\frac{1}{T E R^{*}(t)} \int_{0}^{\infty} \frac{a d(a, t)}{1-r_{p}(t)} d a=M A E(t)$ \\
\hline First birth & $\begin{array}{l}r_{p}(t)=\frac{d M A E(t)}{d t} \\
\text { rate, order } 1, T F R_{1}^{*}(t)\end{array}$ & $\begin{array}{l}\text { No adjustment needed: } \\
M A B_{1}^{*}(t)=M A B_{1}(t)\end{array}$ \\
\hline $\begin{array}{l}\text { First } \\
\text { marriage }\end{array}$ & $\begin{array}{l}\text { Tempo-adjusted total first } \\
\text { marriage rate } T N R_{1}^{*}(t)\end{array}$ & $\begin{array}{l}\text { No adjustment needed: } \\
M A M_{1}^{*}(t)=M A M_{1}(t)\end{array}$ \\
\hline Death & $\begin{array}{l}\text { Tempo-adjusted total } \\
\text { mortality rate } T M R^{*}(t)\end{array}$ & $\begin{array}{l}\text { No adjustment needed: } \\
M A D^{*}(t)=M A D(t)\end{array}$ \\
\hline
\end{tabular}




\begin{tabular}{|c|c|c|}
\hline Event & $\begin{array}{c}\text { Quantum } \\
\text { (total event rate = proportion } \\
\text { ever experiencing event) }\end{array}$ & $\begin{array}{c}\text { Tempo } \\
\text { (mean age at event) }\end{array}$ \\
\hline General & $T E R_{L}(t)=1-\exp \left[-\int_{0} \mu(a, t) d a\right]$ & $\begin{array}{l}\operatorname{MAE}_{L}(t)= \\
\frac{1}{T E R_{L}(t)} \int_{0}^{\infty}\left\{\exp \left[-\int_{0}^{a} \mu(x, t) d x\right]+T E R_{L}(t)-1\right\} d a\end{array}$ \\
\hline $\begin{array}{l}\text { First } \\
\text { birth }\end{array}$ & $T F R_{1 L}(t)$ & $M A B_{1 L}(t)$ \\
\hline $\begin{array}{l}\text { First } \\
\text { marriage }\end{array}$ & $T N R_{1 L}(t)$ & $\operatorname{MAM}_{1 L}(t)$ \\
\hline Death & $T M R_{L}(t)$ & $M A D_{L}(t)$ \\
\hline
\end{tabular}

\begin{tabular}{|c|c|c|}
\hline Event & $\begin{array}{l}\text { Adjusted Quantum } \\
\text { (total event rate) }\end{array}$ & $\begin{array}{l}\text { Adjusted Tempo } \\
\text { (mean age at event) }\end{array}$ \\
\hline General & $T E R_{L}^{*}(t)=1-\exp \left\{-\int_{0}^{\infty} \frac{\mu(a, t)}{1-r_{p}(t)} d a\right\}$ & $\begin{array}{l}M A E_{L}^{*}(t)= \\
\frac{1}{T E R_{I}^{*}(t)} \int_{n}^{\infty}\left\{\exp \left[-\int_{n}^{a} \frac{\mu(x, t)}{1-r_{n}(t)} d x\right]+T E R_{L}^{*}(t)-1\right\} d a\end{array}$ \\
\hline $\begin{array}{l}\text { First } \\
\text { birth }\end{array}$ & $T F R_{L} *(t)$ & $M A B_{L} *(t)$ \\
\hline $\begin{array}{l}\text { First } \\
\text { marriage }\end{array}$ & $T N R_{L} *(t)$ & $M A M_{L} *(t)$ \\
\hline Death & $T M R_{L} *(t)$ & $M A D_{L}^{*}(t)$ \\
\hline
\end{tabular}




\begin{tabular}{|c|c|c|c|c|}
\hline & \multicolumn{4}{|c|}{ Mean age at death, females (average, 1970-1990) } \\
\hline & $\begin{array}{c}M A D(t) \\
\text { (from rates } \\
\text { of the } 2 \mathrm{nd} \\
\text { kind) }\end{array}$ & $\begin{array}{c}M A D_{L}(t)=e_{0}(t) \\
\text { (from rates of the } \\
1 \text { st kind) }\end{array}$ & $\begin{array}{c}M A D_{L}^{*}(t)=e_{0}^{*}(t) \\
\text { (tempo- } \\
\text { adjusted) }\end{array}$ & $\begin{array}{c}\text { Tempo effect } \\
M A D_{L}(t)-M A D_{L}^{*}(t)\end{array}$ \\
\hline Denmark & 76.8 & 78.4 & 76.9 & 1.5 \\
\hline $\begin{array}{l}\text { England/ } \\
\text { Wales }\end{array}$ & 76.9 & 78.3 & 76.8 & 1.4 \\
\hline Sweden & 78.2 & 80.0 & 78.1 & 1.9 \\
\hline
\end{tabular}

Source: Bongaarts and Feeney 2002, 2003. Death rates from University of California, Berkeley Mortality Data Base.

a. With no mortality under age $30, e_{0}(t)=e_{30}(t)+30$ 
Figure 1: Total fertility rate, order one, and mean age at

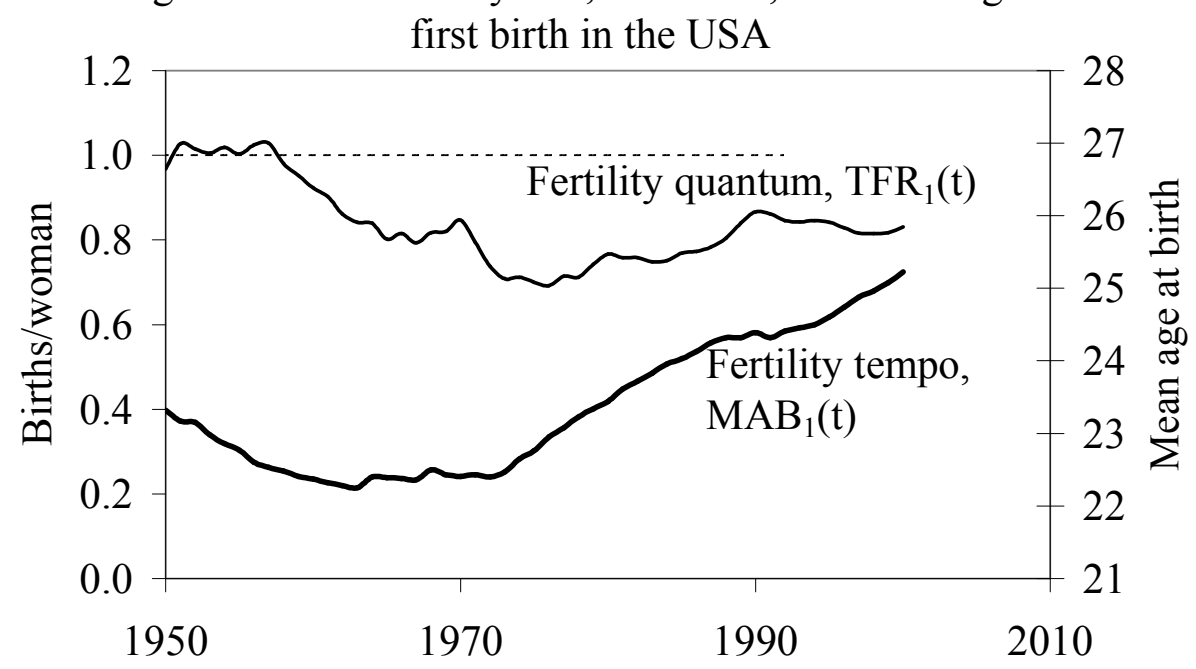

Figure 2: Total first marriage rate and mean age at first marriage, females in France

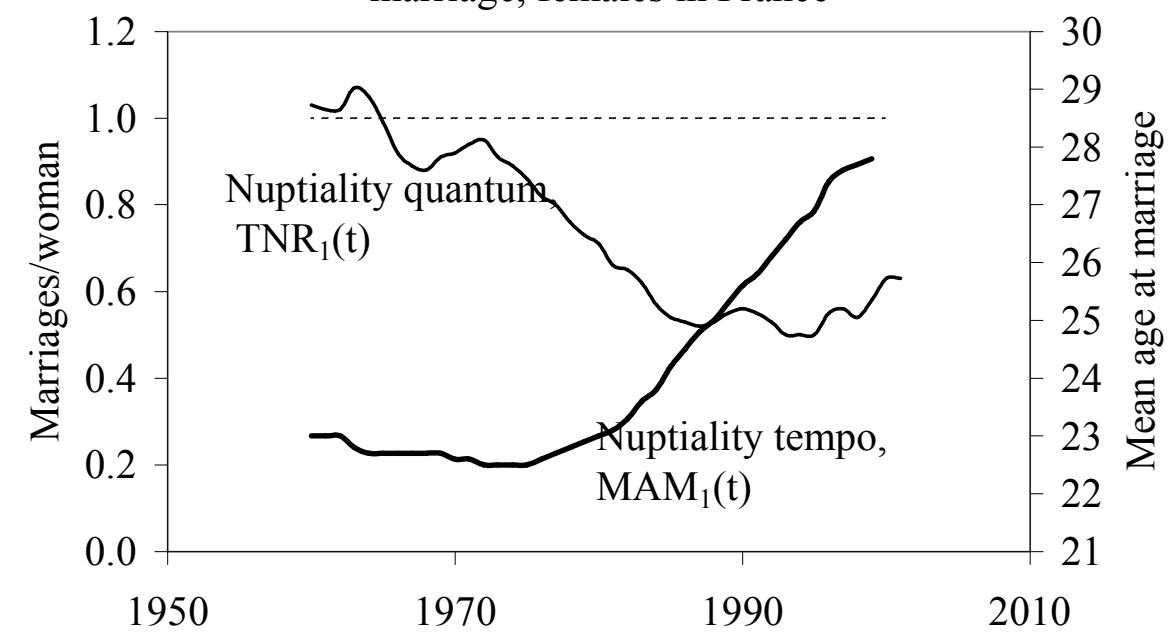

Source: Council of Europe, 2002

Figure 3: Total mortality rate and mean age at death, females in England and Wales (adult mortality only)

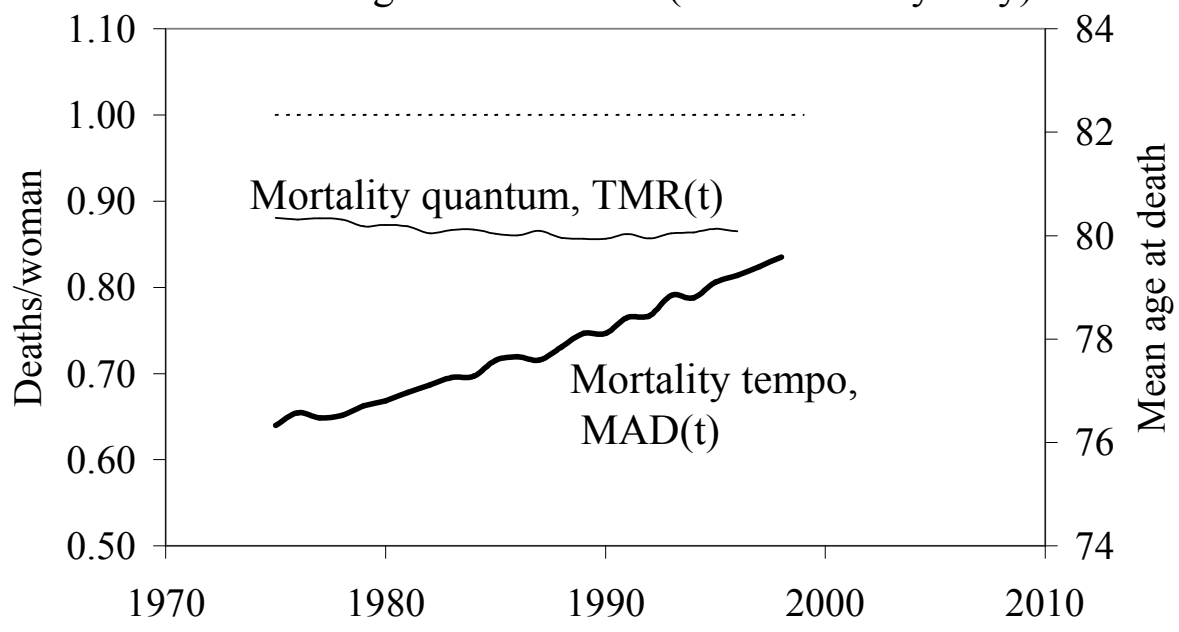

Source: Estimated from data in Human Mortality Database (2005) 
Figure 4: Completed cohort fertility (1960) and period total fertility(1980-89), first births

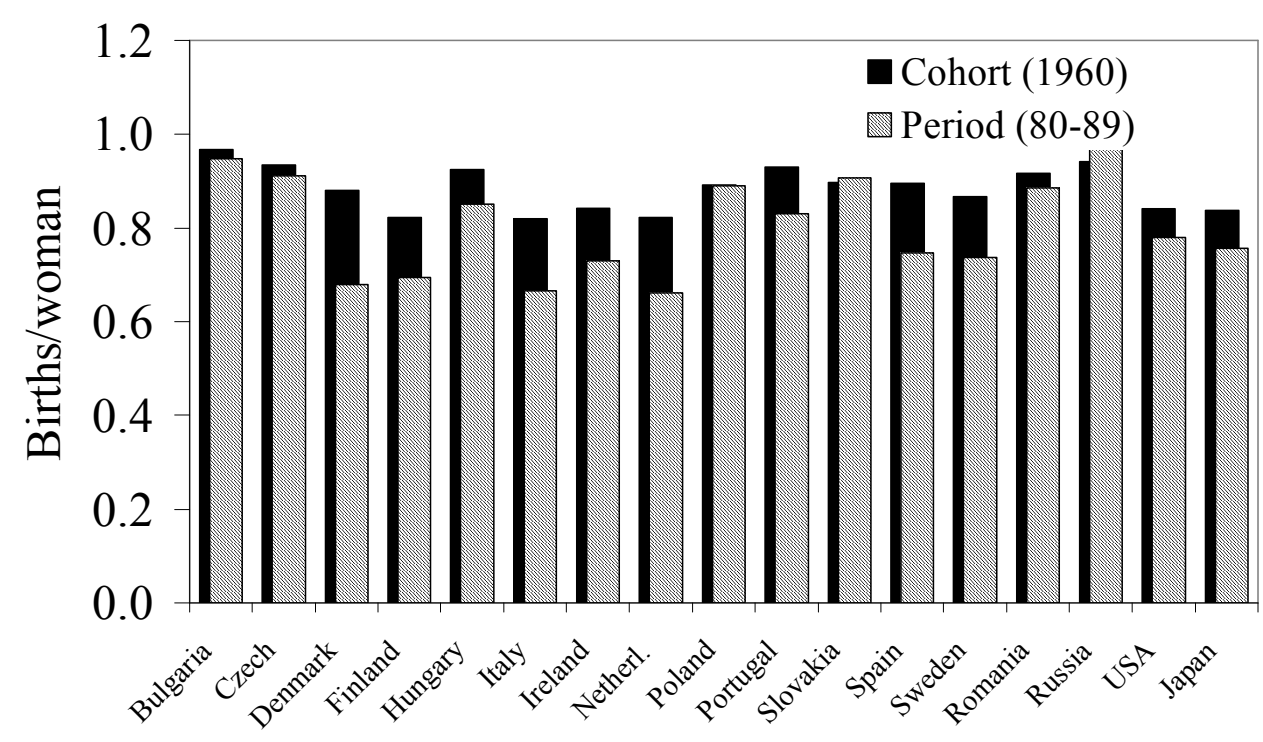

Figure 5: Ratio of period to cohort fertility rate by tempo

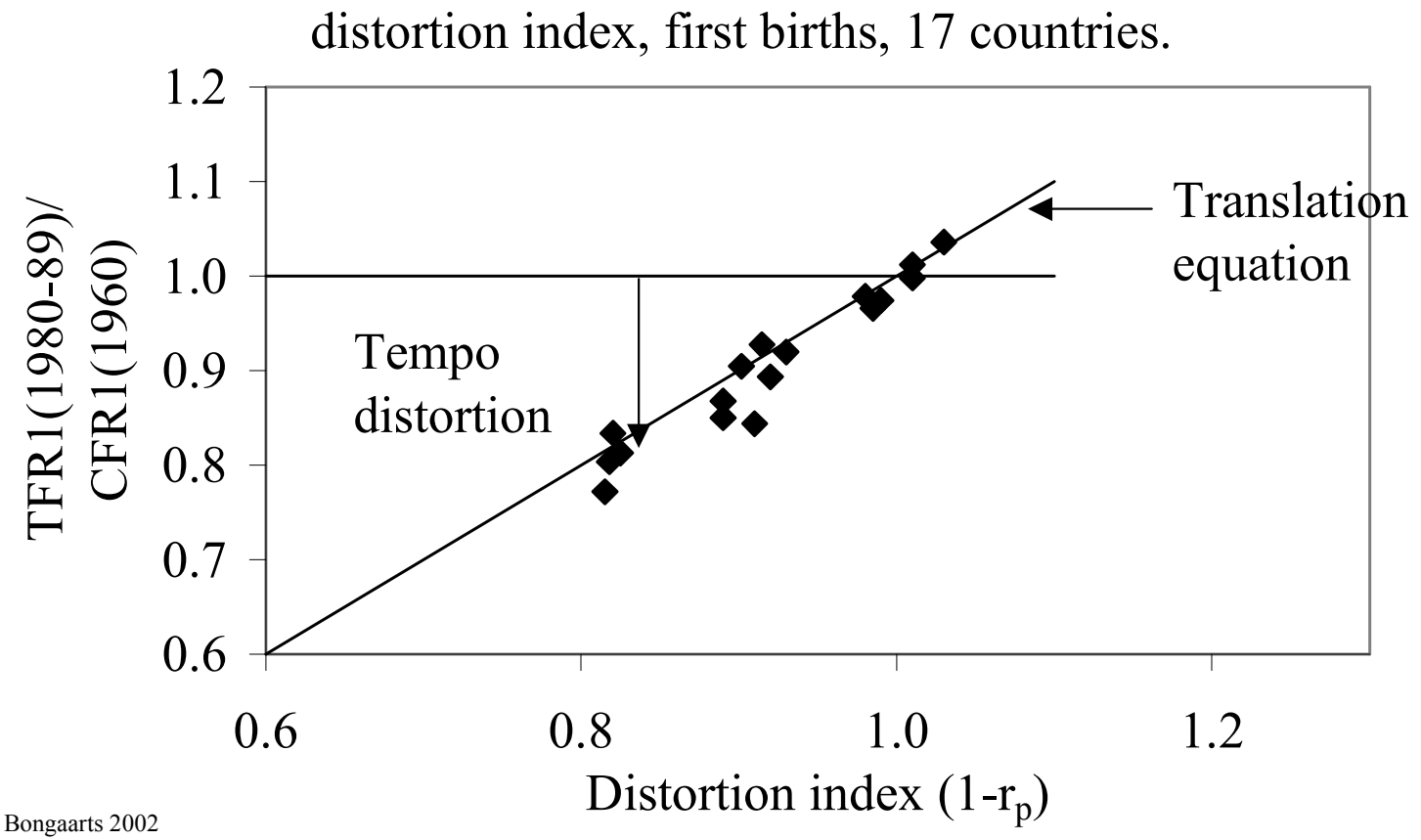


Figure 6: Ratio of period to cohort marriage rate by tempo distortion index, first marriages, 17 countries.

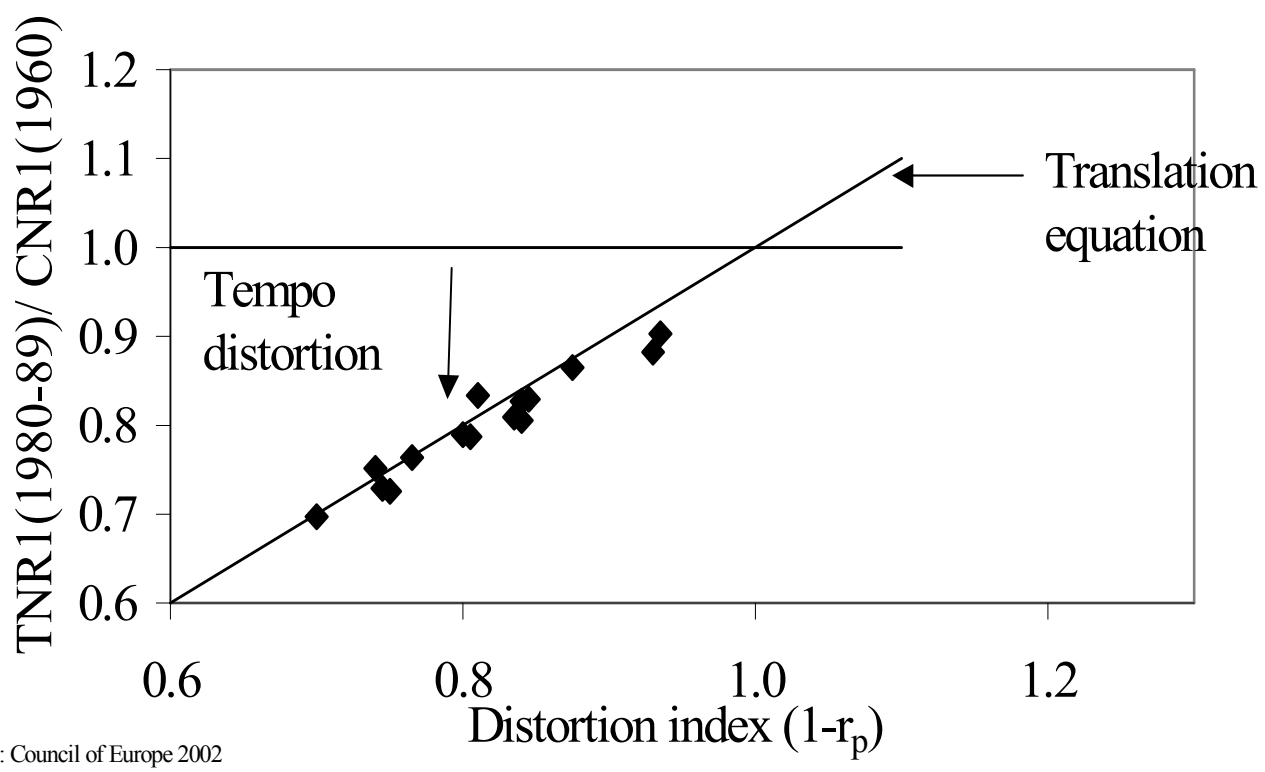

Source: Council of Europe 2002

Figure 7: Period total mortality rate by tempo distortion index, in 7 countries.

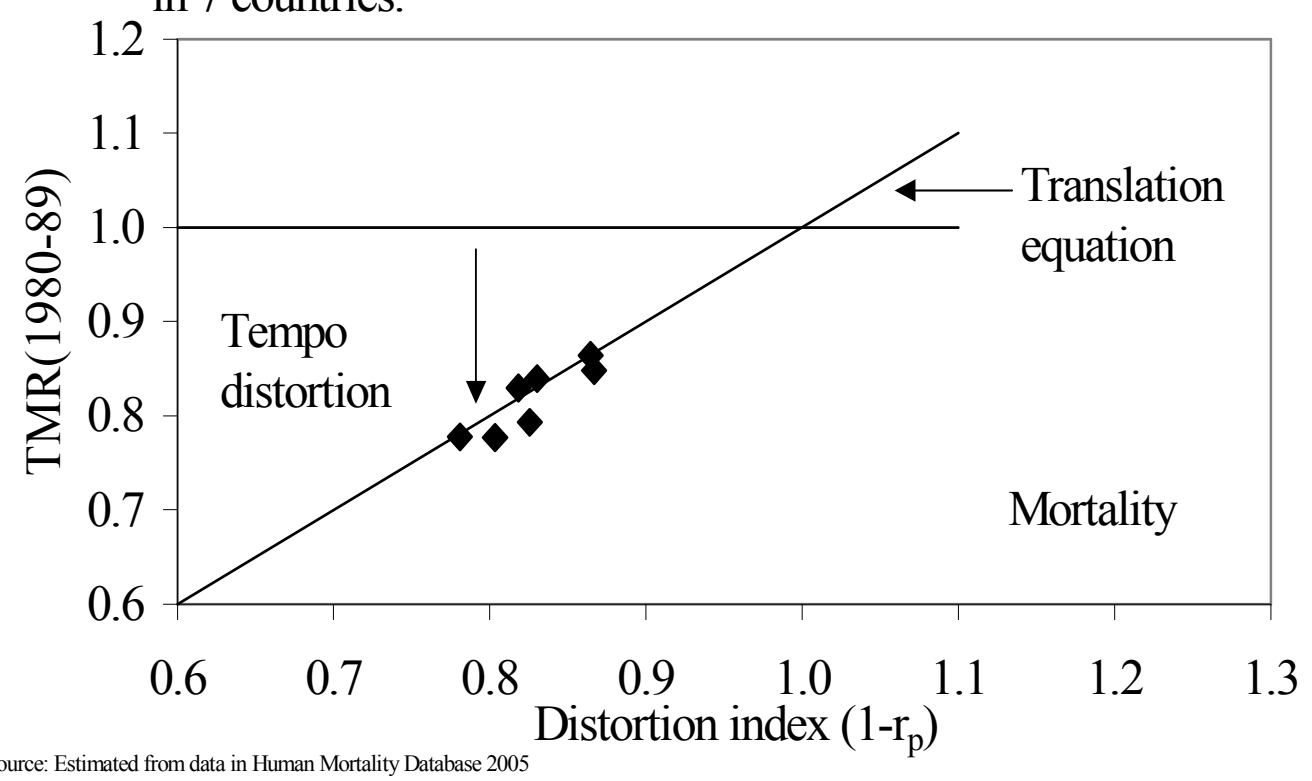


Figure 8: Observed and tempo-adjusted total fertility rate,

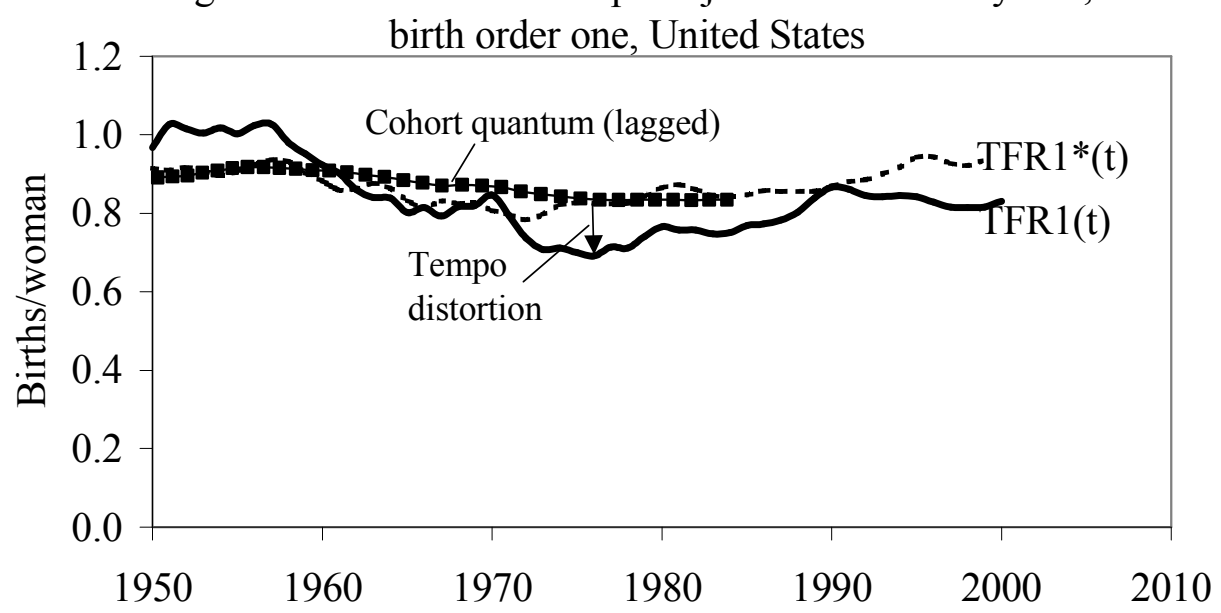

Source: Bongaarts and Feeney, 1998

Figure 9: Observed and tempo-adjusted total first marriage rate, females in France

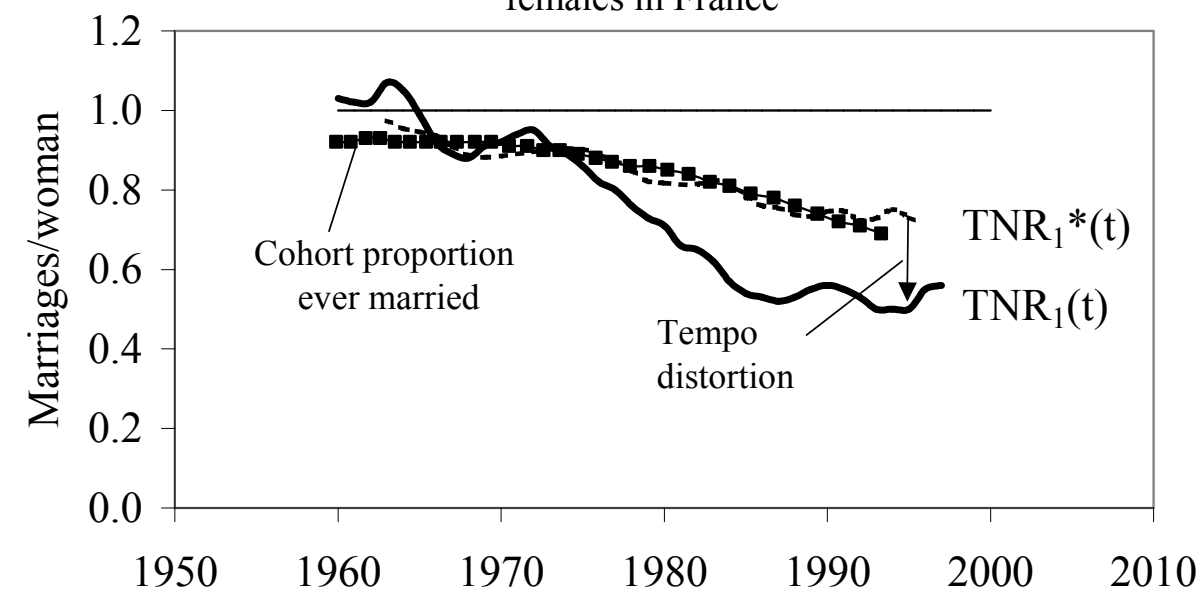

Source: Council of Europe 2002

Figure 10: Observed and tempo-adjusted total mortality rate,

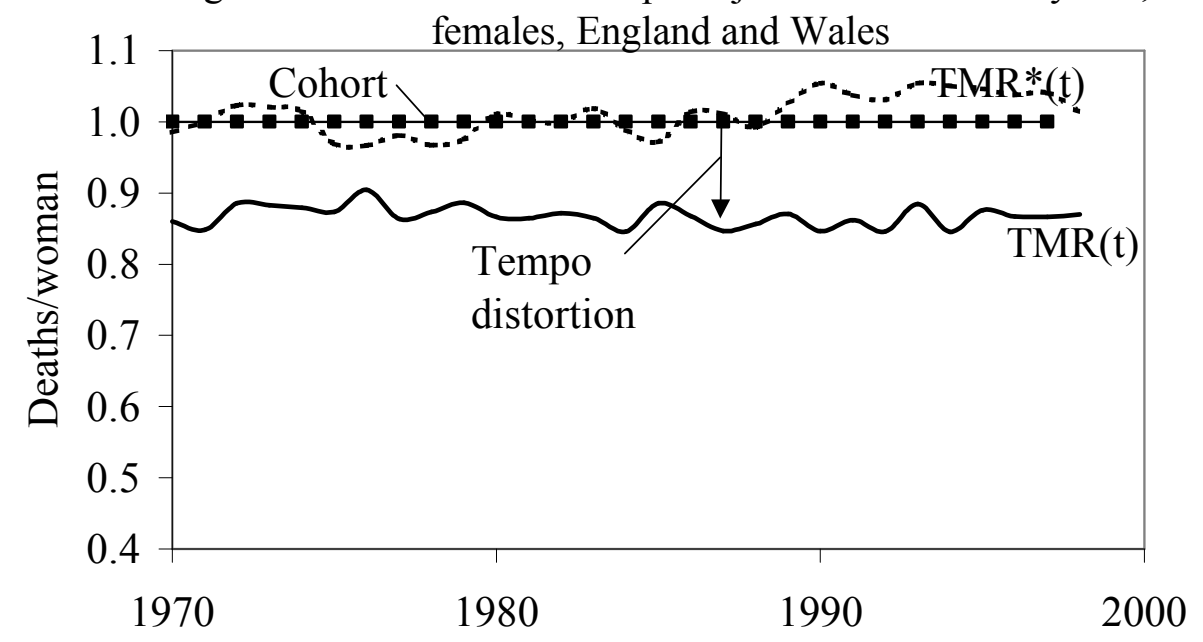

Source: Estimated from data in Human Mortality Database 
Figure 11: Mean age at first birth: Means of 1st and 2nd kind and lagged cohort mean, Czech Republic

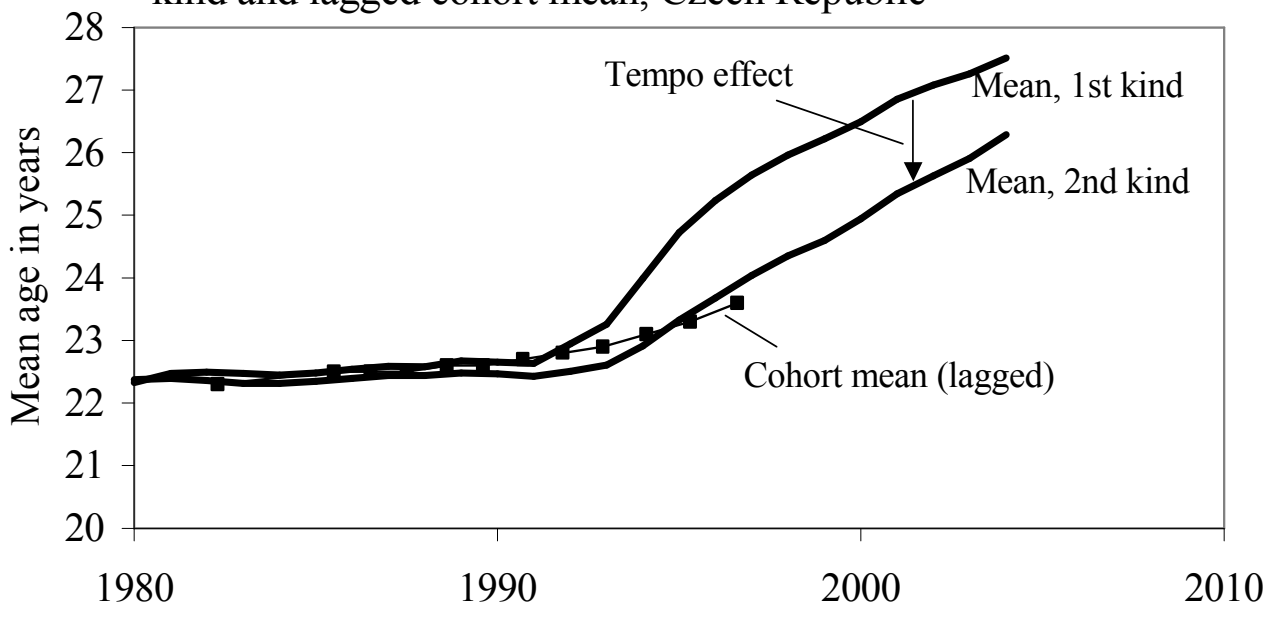

Source: Sobotka, 2004a, Sardon 2004b

Figure 12: Mean age at first birth: Means of 1st and 2nd kind and lagged cohort mean, Netherlands

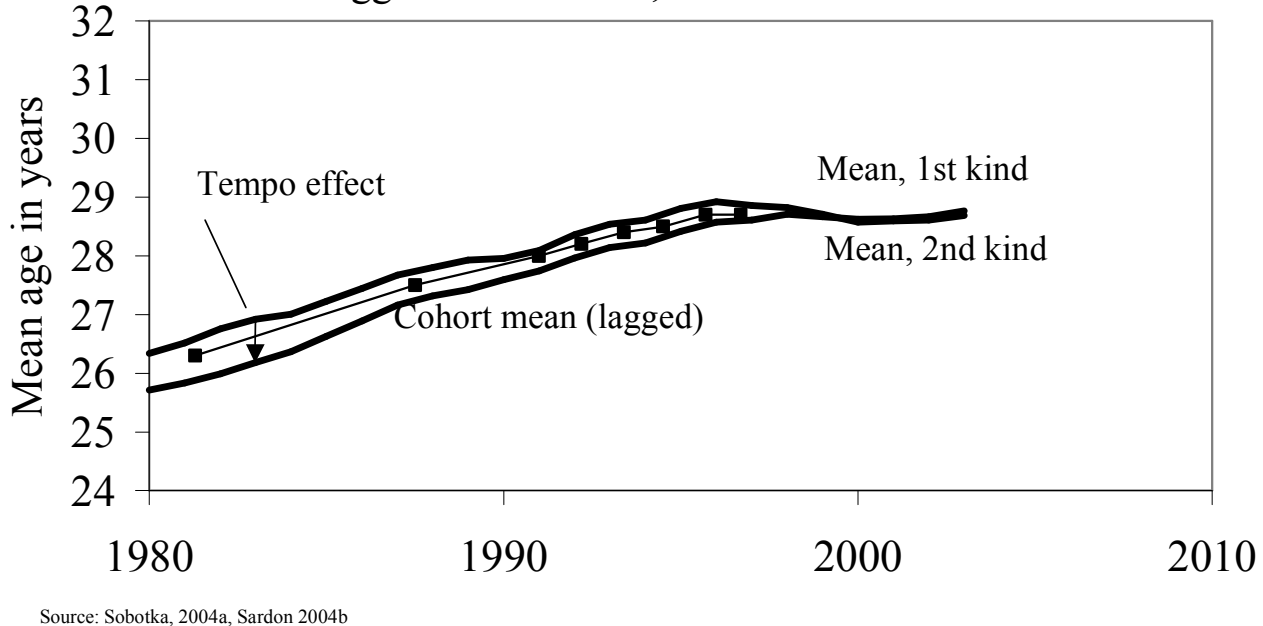

Figure 13: Mean age at first birth: Means of 1st and 2nd kind and lagged cohort mean, Spain

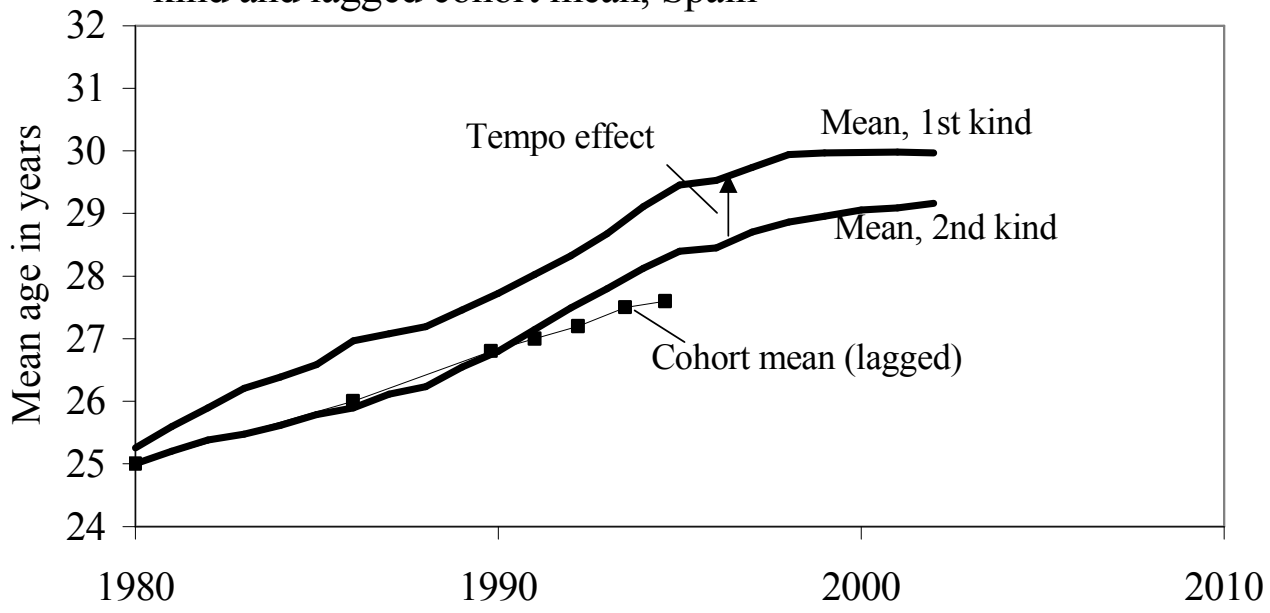

Source: Sobotka, 2004a, Sardon 2004b 
Figure 14: Mean age at death: Means of the 1st and 2nd kind and lagged cohort mean, females in Denmark (no mortality under age 30)

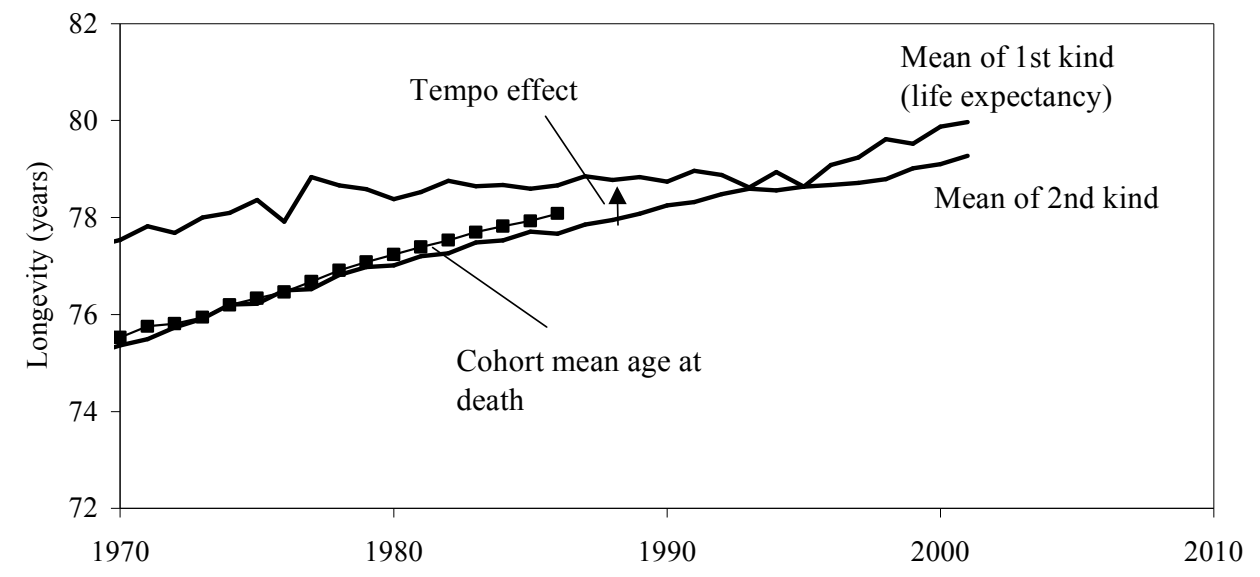

Source: Estimated from data in Human Mortality Database (2005)

Figure 15: Mean age at death: Means of the 1st and 2nd kind and lagged cohort mean, females in England and Wales (no mortality under age 30)

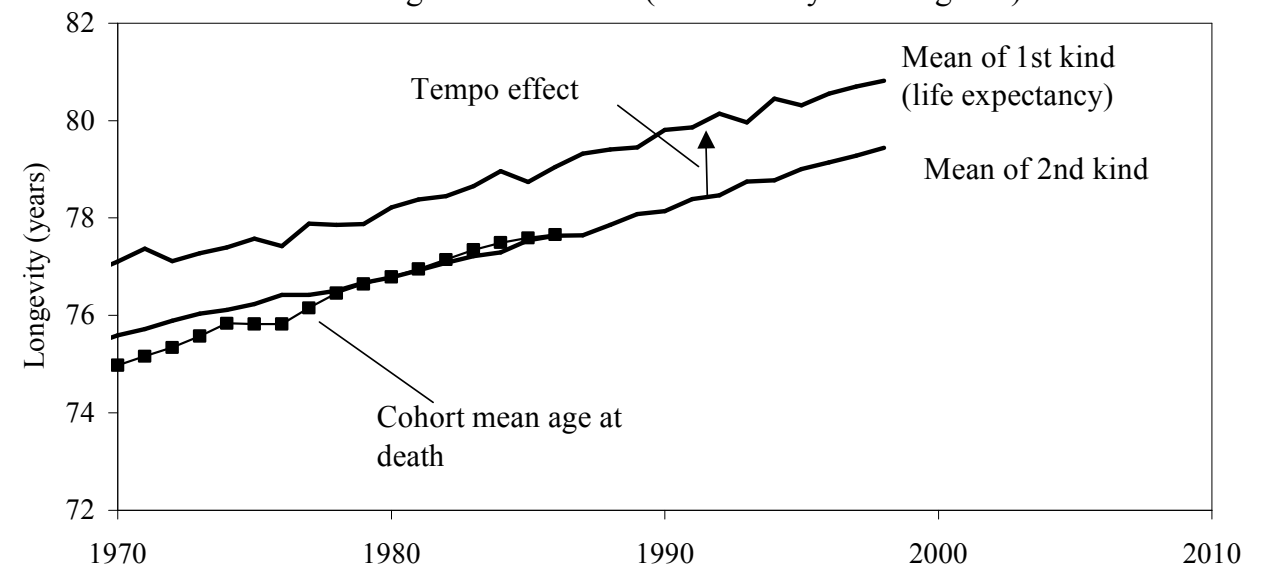

Source: Estimated from data in Human Mortality Database (2005)

Figure 16: Mean age at death: Means of the 1st and 2nd kind and lagged cohort mean, females in Sweden (no mortality under age 30)

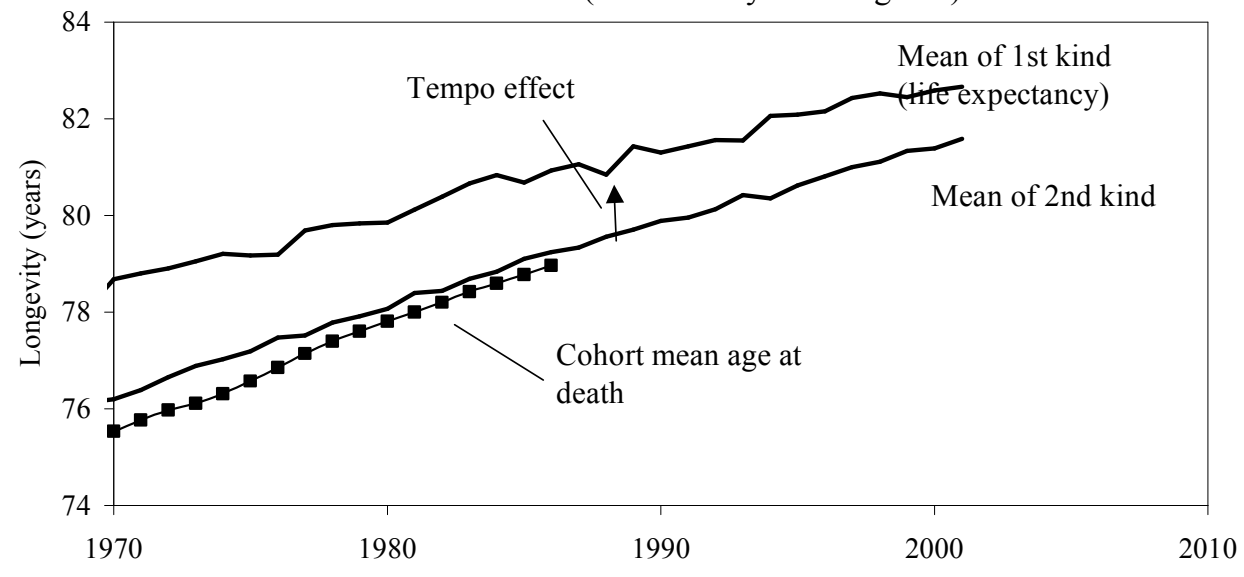

Source: Estimated from data in Human Mortality Database (2005) 
Figure 17: Hypothetical illustration of the effect of an increase in mean age at death on conventionally calculated period life expectancy

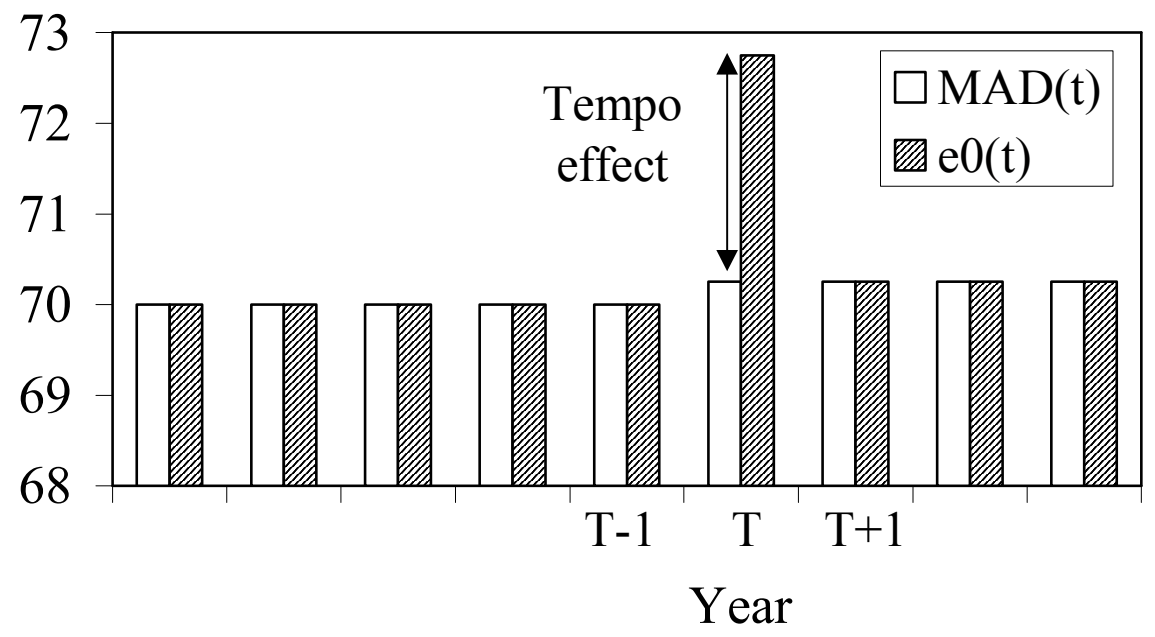




\section{Endnotes}

${ }^{1}$ Zeng and Land (2002) prove this with their assumptions $T F R=C F R /\left(1+r_{c}\right)$ and $r_{c}=r_{p} /\left(1-r_{p}\right)$, where $r_{p}$ is the rate of change of the period mean age of childbearing. Cf. formula (2).

${ }^{2}$ The $T F R$ value is the average $T F R_{1}$ for $1980-89$. The $C F R$ value is $C F R_{1}$ for the 1960 birth cohort. Values of $r_{p}$ are estimated as one tenth of the difference between the period mean ages at first birth in 1980 and 1990.

${ }^{3}$ Application of the tempo-adjustment formulas requires annual estimates of the total event rate and the rate of change in the period mean age of the event. The rate of change during year $t$ is estimated as $0.5[\operatorname{MAE}(t+1)-\operatorname{MAE}(t-1)]$. Application of formulas in Table 4 then gives the time series of tempo-adjusted total event rates. Since the adjustment is sensitive to small errors in $r_{p}(t)$, the annual adjusted estimates tend to contain seemingly random fluctuations. To minimize these fluctuations, we use five-year moving averages of $T E R^{*}(t)$ in place of annual values.

${ }^{4}$ In the case of mortality, the constant shape assumption is applied to adult ages $(30+)$ only. Bongaarts and Feeney (2003) demonstrate that for mortality the constant shape assumption is equivalent to assuming that the survival function $p(a, t)$ shifts to higher or lower ages as the mean age at death rises or falls over time and to assuming that the force of mortality $\mu(a, t)$ is proportional to the relative derivative of the survival function with respect to age.

${ }^{5}$ The estimates of alternative measures of the mean age at death in Tables 7 and Figure 14-16 assume no tempo effects under age 30. For simplicity life expectancy at birth is 
calculated as $e_{0}=30+e_{30}$ and $e_{0}{ }^{*}=30+e_{30} *$, ignoring mortality under age 30 . In countries where mortality under age 30 is not small, we recommend the following more general equations for estimating observed and tempo-adjusted life expectancy:

$$
\begin{aligned}
& e_{0}={ }_{30} L_{0}+l_{30} e_{30} \\
& e_{0}^{*}={ }_{30} L_{0}+l_{30} e_{30} *
\end{aligned}
$$

Note also that Bongaarts and Feeney (2003) use yet another way to calculate the period mean age at death, as $\int_{0}^{\infty} p(a, t) d a$, with $p(a, t)$ denoting the proportion of the cohort born at time $t-a$ who survive to age $a$. This estimate is identical to the variable called $C A L$, the cross-sectional average length of life, introduced by Brouard (1986) and Guillot (2003). 


\section{POLICY RESEARCH DIVISION WORKING PAPERS}

If still in print, single copies of up to three working papers from 1989 through 2003 are available free of charge.

Beginning with the 2004 issues, working papers are no longer available in print format. Instead they are distributed electronically. As each new paper is completed subscribers are notified by e-mail and a link to the paper is provided.

To subscribe to the Policy Research Division working paper e-mail notification list, or to obtain back issues from 1989 to 2003, please send your request to prdwp@popcouncil.org.

PDFs of recent issues are available at www.popcouncil.org/publications/wp/prd/rdwplist.html

2005

207 John Bongaarts and Griffith Feeney, "The quantum and tempo of life-cycle events."

206 Barbara S. Mensch, Monica J. Grant, and Ann K. Blanc, "The changing context of sexual initiation in sub-Saharan Africa."

205 Geoffrey McNicoll, "Population and sustainability."

204 John Bongaarts, "The causes of stalling fertility transitions."

203 Ayaga A. Bawah and Fred N. Binka, "How many years of life could be saved if malaria were eliminated from a hyperendemic area of northern Ghana?"

202 Barbara S. Mensch, Susheela Singh, and John B. Casterline, "Trends in the timing of first marriage among men and women in the developing world."

201 Zachary Zimmer, "Active life expectancy and functional limitations among older Cambodians: Results from a 2004 survey."
200 Brian Wells Pence, Philomena Nyarko, James F. Phillips, and Cornelius Debpuur, "The effect of community nurses and health volunteers on child mortality: The Navrongo Community Health and Family Planning Project."

199 Zachary Zimmer, Linda G. Martin, Mary Beth Ofstedal, and Yi-Li Chuang, "Education of adult children and mortality of their elderly parents in Taiwan."

198 Mian Bazle Hossain, James F. Phillips, and Thomas K. LeGrand, "The impact of childhood mortality on fertility in six rural thanas of Bangladesh."

197 Kristine R. Baker, Mary Beth Ofstedal, Zachary Zimmer, Zhe Tang, and Yi-Li Chuang, "Reciprocal effects of health and economic well-being among older adults in Taiwan and Beijing."

196 Mark R. Montgomery and Paul C. Hewett, "Poverty and children's schooling in urban and rural Senegal." 
2004

195 Luciana Suran, Sajeda Amin, Lopita Huq, and Kobita Chowdury, "Does dowry improve life for brides? A test of the bequest theory of dowry in rural Bangadesh."

194 Barbara S. Mensch, Monica J. Grant, Mary P. Sebastian, Paul C. Hewett, and Dale Huntington. "The effect of a livelihoods intervention in an urban slum in India: Do vocational counseling and training alter the attitudes and behavior of adolescent girls?"

193 Amanda Ritchie, Cynthia B. Lloyd, and Monica Grant. "Gender differences in time use among adolescents in developing countries: Implications of rising school enrollment rates."

192 John Bongaarts. "Long-range trends in adult mortality: Models and projection methods."

191 John Koku Awoonor-Williams, Ellie S. Feinglass, Rachel Tobey, Maya N. Vaughan-Smith, Frank $\mathrm{K}$. Nyonator, Tanya C. Jones, and James F. Phillips, "Bridging the gap between evidence-based innovation and national healthsector reform in Ghana."

190 Kelly Hallman, "Socioeconomic disadvantage and unsafe sexual behaviors among young women and men in South Africa."
Toshiko Kaneda, Zachary

Zimmer, and Zhe Tang, "Differentials in life expectancy and active life expectancy by socioeconomic status among older adults in Beijing."

188 Cynthia B. Lloyd and Monica J. Grant, "Growing up in Pakistan: The separate experiences of males and females."

187 Zachary Zimmer, Xianghua Fang, Toshiko Kaneda, Zhe Tang, and Julia Kwong. "Trends and transitions in children's coresidence with older adults in Beijing municipality."

186 Sajeda Amin and Alaka M. Basu. "Popular perceptions of emerging influences on mortality and longevity in Bangladesh and West Bengal."

185 John Bongaarts. "Population aging and the rising cost of public pensions."

184 Mark R. Montgomery and Paul C. Hewett. "Urban poverty and health in developing countries: Household and neighborhood effects."

\section{3}

183 Agnes R. Quisumbing and Kelly Hallman. "Marriage in transition: Evidence on age, education, and assets from six developing countries." 
182 Paul C. Hewett, Barbara S. Mensch, and Annabel S. Erulkar, "Consistency in the reporting of sexual behavior among adolescent girls in Kenya: A comparison of interviewing methods."

181 Zachary Zimmer, Linda G. Martin, and Hui-Sheng Lin, "Determinants of old-age mortality in Taiwan."

180 Frank K. Nyonator, J. Koku Awoonor-Williams, James F. Phillips, Tanya C. Jones, and Robert A. Miller, "The Ghana Community-based Health Planning and Services Initiative: Fostering evidence-based organizational change and development in a resourceconstrained setting."

179 John Bongaarts and Griffith Feeney, "Estimating mean lifetime."

178 Elizabeth F. Jackson, Patricia Akweongo, Evelyn Sakeah, Abraham Hodgson, Rofina Asuru, and James F. Phillips, "Women's denial of having experienced female genital cutting in northern Ghana: Explanatory factors and consequences for analysis of survey data."

177 John Bongaarts, "Completing the fertility transition in the developing world: The role of educational differences and fertility preferences."

176 Cynthia B. Lloyd and Paul C. Hewett, "Primary schooling in sub-Saharan Africa: Recent trends and current challenges."
175 James F. Phillips, Tanya C. Jones, Frank K. Nyonator, and Shruti Ravikumar, "Evidence-based development of health and family planning programs in Bangladesh and Ghana."

174 Geoffrey McNicoll, "Population and development: An introductory view."

173 Paul Demeny, "Population policy: A concise summary."

172 Zachary Zimmer, Napaporn Chayovan, Hui-Sheng Lin, and Josefina Natividad, "How indicators of socioeconomic status relate to physical functioning of older adults in three Asian societies."

171 Sajeda Amin and Nagah H. AlBassusi, "Wage work and marriage: Perspectives of Egyptian working women."

170 Ravai Marindo, Steve Pearson, and John B. Casterline, "Condom use and abstinence among unmarried young people in Zimbabwe: Which strategy, whose agenda?"

169 Zachary Zimmer and Julia Dayton, "The living arrangements of older adults in sub-Saharan Africa in a time of HIV/AIDS."

168 Paul C. Hewett, Annabel S. Erulkar, and Barbara S. Mensch, "The feasibility of computerassisted survey interviewing in Africa: Experience from two rural districts in Kenya." 